\title{
Uncertainties in Ocean Latent Heat Flux Variations over Recent Decades in Satellite-Based Estimates and Reduced Observation Reanalyses
}

\author{
Franklin R. Robertson, ${ }^{\mathrm{a}}$ JASON B. Roberts, ${ }^{\mathrm{a}}$ MiChAEl G. BOSILOViCh, ${ }^{\mathrm{b}}$

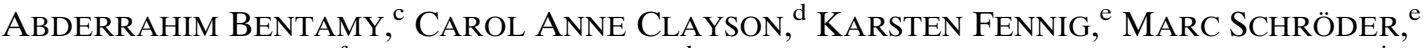 \\ Hiroyuki Tomita, ${ }^{\text {f }}$ Gilbert P. COMPO, ${ }^{\mathrm{g}, \mathrm{h}}$ Marloes Gutenstein, ${ }^{\mathrm{e}}$ Hans Hersbach, ${ }^{\mathrm{i}}$ \\ CHIAKI KOBAYASHI, ${ }^{\mathrm{j}}$ LUCREZIA RICCIARDULLI, ${ }^{\mathrm{k}}$ PRASHANT SARDESHMUKH, ${ }^{\mathrm{g}, \mathrm{h}}$ AND \\ LAURA C. SLIVINSKI ${ }^{\mathrm{g}, \mathrm{h}}$ \\ ${ }^{a}$ NASA Marshall Space Flight Center, Huntsville, Alabama \\ ${ }^{\mathrm{b}}$ NASA GSFC Global Modeling and Assimilation Office, Greenbelt, Maryland \\ ${ }^{c}$ Laboratoire d'Océanographie Spatiale, Institut Français pour la Recheche et l'Exploitation de la Mer (IFREMER), Brest, \\ France \\ ${ }^{\mathrm{d}}$ Woods Hole Oceanographic Institution, Woods Hole, Massachusetts \\ ${ }^{\text {e }}$ Satellite-Based Climate Monitoring, Deutscher Wetterdienst, Offenbach, Germany \\ ${ }^{\mathrm{f}}$ Institute for Space-Earth Environmental Research, Nagoya University, Nagoya, Japan \\ ${ }^{g}$ Cooperative Institute for Research in Environmental Sciences, University of Colorado, Boulder, Colorado \\ ${ }^{\mathrm{h}}$ NOAA Physical Sciences Laboratory, Boulder, Colorado \\ ${ }^{\mathrm{i}}$ European Centre for Medium-Range Weather Forecasts, Reading, United Kingdom \\ ${ }^{\mathrm{j}}$ Meteorological Research Institute, Tsukuba, Japan \\ ${ }^{\mathrm{k}}$ Remote Sensing Systems, Santa Rosa, California
}

(Manuscript received 20 December 2019, in final form 3 June 2020)

\begin{abstract}
Four state-of-the-art satellite-based estimates of ocean surface latent heat fluxes (LHFs) extending over three decades are analyzed, focusing on the interannual variability and trends of near-global averages and regional patterns. Detailed intercomparisons are made with other datasets including 1) reduced observation reanalyses (RedObs) whose exclusion of satellite data renders them an important independent diagnostic tool; 2) a moisture budget residual LHF estimate using reanalysis moisture transport, atmospheric storage, and satellite precipitation; 3) the ECMWF Reanalysis 5 (ERA5); 4) Remote Sensing Systems (RSS) singlesensor passive microwave and scatterometer wind speed retrievals; and 5) several sea surface temperature (SST) datasets. Large disparities remain in near-global satellite LHF trends and their regional expression over the 1990-2010 period, during which time the interdecadal Pacific oscillation changed sign. The budget residual diagnostics support the smaller RedObs LHF trends. The satellites, ERA5, and RedObs are reasonably consistent in identifying contributions by the $10-\mathrm{m}$ wind speed variations to the LHF trend patterns. However, contributions by the near-surface vertical humidity gradient from satellites and ERA5 trend upward in time with respect to the RedObs ensemble and show less agreement in trend patterns. Problems with wind speed retrievals from Special Sensor Microwave Imager/Sounder satellite sensors, excessive upward trends in trends in Optimal Interpolation Sea Surface Temperature (OISST AVHRR-Only) data used in most satellite LHF estimates, and uncertainties associated with poor satellite coverage before the mid-1990s are noted. Possibly erroneous trends are also identified in ERA5 LHF associated with the onset of scatterometer wind data assimilation in the early 1990s.
\end{abstract}

\footnotetext{
${ }^{1}$ See the AMS site https://www.ametsoc.org/PubsAcronymList for acronyms and abbreviations not explained in the text.
}

Corresponding author: Franklin R. Robertson, pete.robertson@ nasa.gov

\section{Introduction}

Latent heat flux $\left(\mathrm{LHF}^{1}\right)$ is a major linkage between the global ocean and overlying atmosphere, directly controlling the mass and energy exchanges between them. Each of the seven WCRP Grand Challenges 
(https://www.wcrp-climate.org/grand-challenges/grandchallenges-overview) involves the hydrosphere and requires improved process understanding, more accurate measurement, and improved modeling of water cycle fluxes. Addressing the question of "How is the water cycle changing?" has important hydrologic and planetary energy balance aspects that require LHF accuracy beyond that currently provided by satellite-based estimates or in situ data. At multidecadal to centennial time scales, atmospheric radiative constraints on hydrological trends are expected to hold increases in global mean precipitation $P$ or evaporation $E^{2}$ to less than a $2 \% \mathrm{~K}^{-1}$ rise in global surface temperature rise (Manabe and Wetherald 1975; Allen and Ingram 2002). This contrasts with changes in the water holding capacity of the atmosphere that roughly scale at the Clausius-Clapeyron rate of $\sim 7 \% \mathrm{~K}^{-1}$ temperature rise (Held and Soden 2006). On interannual to decadal scales, natural climate variability is enhanced by coupled atmosphere-oceanland dynamics (Allan et al. 2013; Trenberth and Fasullo 2013; Miralles et al. 2014). Because the observational record from satellites now barely encompasses multidecadal time scales, detecting and separating these two components using models and observations remains problematic. Climate variability accessible since the beginning of passive microwave satellite data is largely that of ENSO and interdecadal signals such as the IPO (Power et al. 1999; Henley et al. 2015) and the so-called warming hiatus during the 2000s (Easterling and Wehner 2009; Kosaka and Xie 2013).

From a hydrologic cycle perspective, evaporation plays a major role in ocean surface salinity changes (Durack and Wijffels 2010; Helm et al. 2010) and on shorter time scales, ocean mass balance (Boening et al. 2012; Cazenave et al. 2012; Stammer et al. 2013). Quantifying freshwater flux $(E-P)$ and global ocean mass changes potentially also enables accurate land discharge estimates (Syed et al. 2010). Reconciling satellite-derived $E-P$ and reanalysis moisture flux divergence with space-based ocean altimetric and gravimetric water storage histories is a promising area of active research (Chen et al. 2005; Trenberth and Fasullo 2013; Rodell et al. 2015). How these variations behave in the emerging multidecadal record and how refined ocean evaporation estimates, particularly in concert with precipitation, can contribute is an urgent question.

From a planetary energy balance perspective, satellite LHF estimates have been far too uncertain to assist in determining ocean heat storage. Reanalysis vertically integrated energy flux divergence and observed TOA

\footnotetext{
${ }^{2} E=\mathrm{LHF} / L_{v} \rho_{o}$, where $L_{v}$ is the latent heat of evaporation and $\rho_{o}$ is ocean water density.
}

fluxes have been used together to arrive at the net surface energy exchange as a residual (Trenberth 1997; Liu et al. 2015, 2017). Interannual variations in TOA fluxes (Loeb et al. 2012) are of the same size as current estimates of Earth's energy imbalance (EEI) at TOA -in the range of 0.6-1.2 $\mathrm{W} \mathrm{m}^{-2}$ (Roemmich et al. 2015; von Schuckmann et al. 2016; Cheng et al. 2017). At present we have little understanding of how the net surface flux components vary together in time as ocean heat storage changes and how LHF changes come into play.

Can we expect improved remote sensing strategies to meet these challenges? Passive and active microwave satellite observations can determine near-surface humidity, temperature, and wind speed and have now amassed $30+$ years of data. When coupled with SST retrievals and applied as input to comprehensive bulk parameterization retrievals of LHF (Fairall et al. 2003; Edson et al. 2013), satellite-based LHF datasets have yielded encouraging improvements (Liu 1984, 1988; Schulz et al. 1993; Bentamy et al. 2003, 2013, 2017; Yu 2019). The bulk method takes the form

$$
\mathrm{LHF}=L_{v} \rho_{o} C_{E} U\left(Q_{s}-Q_{a}\right),
$$

where $Q_{s}$ and $Q_{a}$ are specific humidities of the ocean surface and overlying atmosphere (typically at $2 \mathrm{~m}$ ), $U$ is $10-\mathrm{m}$ wind speed, $\rho_{o}$ is atmospheric density, $L_{v}$ is the latent heat of evaporation, and $C_{E}$ is the exchange coefficient (Dalton number).

However, persistent challenges have made the development of stable LHF climate records problematic. Sensor-related issues include orbital drift through the diurnal cycle, sensor Earth incidence angle variations, on-board calibration stability, changing antenna emissivity, variable channel central frequency, and footprint size. Determining accurate differences between $Q_{s}$ and $Q_{a}$ from space is difficult since passive microwave channel weighting functions are broad and do not directly measure the near-surface humidity; rather, they determine the lower tropospheric water vapor burden, which is reasonably correlated with 2-m $Q_{a}$ (Schulz et al. 1993). The character of $Q_{a}$ variability itself depends on different "dynamical weather regimes" such as warm pool quasi-equilibrium radiative/convective balance, subtropical subsidence, or midlatitude baroclinic weather systems (Yu 2019; Roberts et al. 2019). Passive microwave wind speed retrievals, while more directly related to surface wind stress, are sensitive to temporal stability in the $37-\mathrm{GHz}$ channels that, as we will see later, are more problematic in the SSMIS than the SSM/I sensors. Additionally, both near-surface $Q_{a}$ and wind speed retrievals have regime biases from the presence of cloud liquid water and its links to atmospheric dynamics. Uncertainties 
in SST and, thus, $Q_{s}$ have received less scrutiny than $Q_{a}$ in the context of developing ocean LHF estimates. But SST records typically involve multiple observing platforms, both in situ and space-based. We will see that differences among SST climate data records have important consequences for decadal variability of LHF estimates.

Nevertheless, these error sources are gradually being reduced. As one example, recent algorithm advances (Bentamy et al. 2013; Tomita et al. 2018; Roberts et al. 2020) have incorporated ancillary information accounting for water vapor scale height and/or SST changing with dynamical regime. Merged passive/active wind speed estimates as climate records are maturing steadily (Bentamy et al. 2012, 2017; Wentz et al. 2017). Many of these same problems of sensor calibration and regime-dependent biases still affect satellite-derived precipitation (Adler et al. 2018) and thus, $E-P$ retrievals. Accuracy and availability of in situ training/validation data (Berry and Kent 2017) remain persistent challenges although continuing data recovery efforts benefit in situ records (Freeman et al. 2017).

Comprehensive or "full input" reanalyses assimilate a broad array of observations including passive and active microwave radiances and retrievals (Fujiwara et al. 2017). Through parameterized physics they provide an internally consistent framework for simultaneously determining turbulent and radiative fluxes. But because model physics are imperfect, assimilating models tend to drift toward their own climate in the absence of sufficient observational data to constrain analyses. Consequently, the continual but discrete introduction of new satellite sensors in recent decades has resulted in offsets or steps in fluxes and other variables that can distort natural variability and induce artificial trends (Trenberth and Fasullo 2013; Robertson et al. 2014). One class of reanalyses, which we refer to as reduced observation reanalyses (RedObs), assimilates varying degrees of only conventional in situ observations, thus permitting much longer study periods. Although these products may lack details and fidelity in their depiction of weather in a deterministic sense and systematic model physics biases undoubtedly persist, evidence is emerging that they capture interannual to decadal signals reasonably well (Compo et al. 2011; Feng et al. 2018; Laloyaux et al. 2018). RedObs do share SST and sea ice forcing used in comprehensive reanalyses but their omission of satellite temperature, moisture, and wind speed retrievals makes them valuable for intercomparison and a contribution to validation. There are caveats, of course. The model moisture fields (e.g., $Q_{a}$ ) are controlled by model physics. Declines in some marine data observations (Kent et al. 2006) also likely have some effect. We interpret these datasets as a compromise between AMIP experiments, where lower boundary forcing and radiative forcing are the only external constraints, and conventional reanalyses that have to accommodate tremendous changes in observing systems. The RedObs strength of greater internal consistency in flux products because of smaller assimilation increments is used in this study to help identify uncertainties in satellite derived LHF estimates. Our analysis provides additional diagnostic results that support the utility and interpretation of RedObs products.

Our objectives in this work are threefold: 1) to quantify interannual to interdecadal LHF variability in recent updates to ocean satellite-derived LHF estimates; 2) to trace differences in LHF variability to differences in satellite-derived wind speed and near-surface humidity forcing for bulk aerodynamic estimates; and 3) to assess the consistency between satellite-estimated and RedObs LHF variability and determine to what extent these simpler reanalyses can be used as a partial validation source to identify potential quality issues.

\section{Datasets and methodology}

Our analysis will focus exclusively on variability of monthly mean values rather than climatological structure. The common period 1992 through 2010 is used to define monthly resolved climatologies of each dataset which, when subtracted from the total fields, yield monthly anomalies. This period is bounded by the beginning of IFREMER4.1 (Institut Français pour la Recherche et l'Exploitation de la Mer, version 4.1) and the end of CERA-20C (ECMWF coupled ERA twentieth century integration) archives. While most LHF estimates are produced at $0.25^{\circ}$ resolution, all data used here were either accessed at or remapped to common $1.0^{\circ}$ grids. We use the region $60^{\circ} \mathrm{N} / \mathrm{S}$ to represent the global domain, acknowledging that important variability in polar regions exists but is fraught with problems in current satellite estimates because of undetected sea ice and a lack of in situ validation data.

\section{a. Satellite-derived bulk estimates}

In addition to the discussion below, further details of the satellite algorithms and reanalysis properties are presented in Tables 1 and 2, respectively. An important point for the satellite LHF estimates is that the starting Level 1B Fundamental Climate Data Records (FCDRs) of sensor channel brightness temperature $(\mathrm{Tb})$ differ for each algorithm as noted below and in Table 1. While all estimates are based on the COARE bulk algorithm (Fairall et al. 2003), version updates vary among the four systems.

\section{1) IFREMER4.1}

Bentamy et al. (2013) detail the updated empirical model for $Q_{a}$ used in the latest version of air-sea fluxes 
TABLE 1. Properties of the four satellite-based latent heat flux retrieval algorithms. See text in section 2a for a more detailed description of individual algorithms. Also see section 2a for references and brief discussion of OAFlux V3, a blended satellite/reanalysis product.

\begin{tabular}{|c|c|c|c|c|c|}
\hline Dataset (institution) & $\begin{array}{l}\text { Level-2 retrieval } \\
\text { collocation }\end{array}$ & $Q_{a}$ & Wind speed & SST & $\begin{array}{c}\text { Data availability and } \\
\text { references }\end{array}$ \\
\hline \multirow[t]{2}{*}{$\begin{array}{l}\text { IFREMER v4.1 } \\
\text { (Institut Français } \\
\text { pour la Recherche } \\
\text { et l'Exploitation } \\
\text { de la Mer) }\end{array}$} & $\begin{array}{l}\text { NOCS } 2.0 \mathrm{q} 10 \mathrm{~m} \text { and } \\
\text { SSM/I(IS) satellite } \\
\text { matchups done at } \\
0.25^{\circ} \text { if occurring } \\
\text { on the same day } \\
\text { and if the } \\
\text { separation } \\
\text { distance is less } \\
\text { than } 100 \mathrm{~km}\end{array}$ & $\begin{array}{l}\text { In addition to } \\
\text { satellite Tb } \\
\text { retrieval } \\
\text { predictors include } \\
\text { OISST-AVHRR- } \\
\text { Only SST and } \\
\text { ERA-I SST and } \\
T_{2 \mathrm{~m}} \text { difference }\end{array}$ & $\begin{array}{l}\text { Bentamy et al. } \\
\text { (2017); ERS-1, } \\
\text { ERS-2, } \\
\text { QuikSCAT and } \\
\text { ASCAT RSS V7 } \\
\text { wind speeds used } \\
\text { as ancillary data to } \\
\text { gap fill } \\
\text { scatterometers }\end{array}$ & $\begin{array}{l}\text { AVHRR-Only SST } \\
\text { (Reynolds } \\
\text { et al. 2007) }\end{array}$ & $\begin{array}{c}\text { Data: ftp://o1ef56@ } \\
\text { eftp.ifremer.fr/ } \\
\text { oceanheatflux/ } \\
\text { data/third-party/ } \\
\text { fluxes/ifremerflux_ } \\
\text { v4.1_monthly/ }\end{array}$ \\
\hline & $\begin{array}{l}\text { ERA-Interim Q10 } \\
\text { and T10m } \\
\text { occurring if within } \\
50 \mathrm{~km} \text { and } 3 \mathrm{~h} \text { of } \\
\mathrm{SSM} / \mathrm{I}(\mathrm{IS})\end{array}$ & $\begin{array}{l}\text { An external drift } \\
\text { constraint at the } \\
\text { daily level is } \\
\text { applied via use } \\
\text { ERA-I q2mm }\end{array}$ & & & $\begin{array}{l}\text { Retrieval algorithm: } \\
\text { Bentamy et al. } \\
\text { (2013, 2017); wind } \\
\text { speed: Bentamy } \\
\text { et al. (2017) }\end{array}$ \\
\hline $\begin{array}{l}\text { HOAPS } 4 \text { (Hamburg } \\
\text { Ocean } \\
\text { Atmosphere } \\
\text { Parameters and } \\
\text { Fluxes from } \\
\text { Satellite Data) }\end{array}$ & $\begin{array}{l}\mathrm{SSM} / \mathrm{I}(\mathrm{IS}) \text { retrievals } \\
\text { at swath level } \\
\text { (HOAPS-S); } \\
\text { HOAPS-C, G } \\
\text { aggregate to } 6 \mathrm{~h} \\
\text { and monthly } 0.5^{\circ} \\
\text { respectively; } \\
\text { upgraded } \\
\text { COARE } 2.6 \text { flux } \\
\text { retrievals }\end{array}$ & $\begin{array}{l}\text { Linear regression of } \\
\text { 19V, H, 22V, } \\
\text { 37VH; trained } \\
\text { with } 1 \text { yr of } \\
\text { Atlantic ICOADS } \\
\text { ship data } \\
\text { (Bentamy } \\
\text { et al. 2003) }\end{array}$ & $\begin{array}{l}\text { 1D-VAR retrieval of } \\
\text { 10-m wind speed } \\
\text { and column water } \\
\text { vapor; fixed } \\
\text { ECMWF forecast } \\
\text { climatological } \\
\text { background } \\
\text { atmospheric } \\
\text { profiles with } \\
\text { RTTOVS forward } \\
\text { modeling of TBs }\end{array}$ & $\begin{array}{l}\text { NOAA } 0.25^{\circ} \text { daily } \\
\text { OISST, version } 2 \text {, } \\
\text { AVHRR-Only } \\
\text { (Reynolds et al. } \\
\text { 2007; Reynolds } \\
\text { 2009); skin tem- } \\
\text { perature estimate } \\
\text { follows Donlon } \\
\text { et al. (2002) }\end{array}$ & $\begin{array}{l}\text { https://doi.org/ } \\
\text { 10.5676/EUM_ } \\
\text { SAF_CM/ } \\
\text { HOAPS/V002 } \\
\text { FCDR: Fennig } \\
\text { et al. (2019) } \\
\text { Andersson } \\
\text { et al. (2010) }\end{array}$ \\
\hline $\begin{array}{l}\text { J-OFURO3 } \\
\text { (Japanese Ocean } \\
\text { Flux Datasets with } \\
\text { Use of Remote } \\
\text { Sensing } \\
\text { Observations) }\end{array}$ & $\begin{array}{l}\text { COARE } 3.0 \text { driven } \\
\text { with daily means } \\
\text { of input variables } \\
\text { on } 0.25^{\circ} \text { grid }\end{array}$ & $\begin{array}{l}\text { RSS column water } \\
\text { vapor } W \text { and } \\
\text { ERA-I and } \\
\text { ICOADS } 10 \text {-m } \\
\text { moisture } q_{v} \text { are } \\
\text { used to define } \\
\text { water vapor scale } \\
\text { height, } H_{v}=W / \\
\left(\rho_{a} q_{v}\right) \text { over six } \\
\text { different moisture } \\
\text { stratification } \\
\text { regimes enabling } \\
Q_{a}=Q_{a}\left(\mathrm{~Tb}, H_{v}\right) \\
\text { retrieval }\end{array}$ & $\begin{array}{l}\text { RSS V7.1 retrievals: } \\
\text { SSM/I, SSM/IS, } \\
\text { AMSR-E, TMI, } \\
\text { WindSat, AMSR2, } \\
\text { ERS- } 1 \text { and } E R S-2, \\
\text { QuikSCAT, } \\
\text { ASCATA, } \\
\text { OSCAT, NOAA } \\
\text { ASCAT/B }\end{array}$ & $\begin{array}{l}\text { Ensemble-median } \\
\text { SST blends } \\
12 \text { Level-3 and } \\
-4 \text { datasets to } \\
\text { reduce random } \\
\text { error yet minimize } \\
\text { rms departures } \\
\text { from buoys }\end{array}$ & $\begin{array}{l}\text { Data: https://j- } \\
\quad \text { ofuro.scc.u- } \\
\text { tokai.ac.jp } \\
\text { Tomita et al. (2019) } \\
\text { Tomita et al. (2018) }\end{array}$ \\
\hline \multirow[t]{2}{*}{$\begin{array}{l}\text { SeaFlux V3 (NASA } \\
\text { MSFC/Woods } \\
\text { Hole } \\
\text { Oceanographic } \\
\text { Institution) }\end{array}$} & $\begin{array}{l}\text { Neural net algorithm } \\
\text { trained using 3-h } \\
\text { window } \\
\text { collocations of } \\
\text { ICOADS V3 and } \\
\text { swath data on } \\
0.25^{\circ} \text { grid }\end{array}$ & \multicolumn{2}{|c|}{$\begin{array}{l}\text { MERRA-2 a priori estimates of water vapor } \\
\text { stratification and the surface to } 850-\mathrm{hPa} \\
\text { mean layer temperature to address the } \\
\text { regional biases found in Roberts } \\
\text { et al. (2019) }\end{array}$} & $\begin{array}{l}\text { NOAA } 0.25^{\circ} \text { daily } \\
\text { OISST V2, } \\
\text { AVHRR-only } \\
\text { with a specified } \\
\text { diurnal cycle } \\
\text { applied as input is } \\
\text { weakly impacted }\end{array}$ & Roberts et al. (2010) \\
\hline & $\begin{array}{l}\text { AMSR-E, TRMM, } \\
\text { AMSR2, GPM } \\
\text { sensors included; } \\
\text { COARE } 3.5 \text { flux } \\
\text { retrievals }\end{array}$ & $\begin{array}{r}Q_{a} \text { and } 10-\mathrm{m} \text { wind } \\
10 \text {-node, one } \mathrm{h} \\
\text { net a }\end{array}$ & $\begin{array}{l}\text { speed output from } \\
\text { idden layer neural } \\
\text { lgorithm }\end{array}$ & $\begin{array}{l}\text { by the NN } \\
\text { retrieval }\end{array}$ & Roberts et al. (2020) \\
\hline
\end{tabular}

produced by the IFREMER4.1 (hereafter IFREMER4). Estimates of $Q_{a}$ use $\mathrm{Tb}$ from the Colorado State University (CSU FCDR; Kummerow et al. 2013), and the latest reprocessed International Comprehensive
Ocean-Atmosphere Dataset (ICOADS version 3; Freeman et al. 2017) as input. To extend the flux record beyond the CSU FCDR's end in June 2017, the Remote Sensing Systems (RSS) FCDR (Wentz 2013) Tb values are used. 
TABLE 2. Relevant properties of reduced observations reanalyses (RedObs) and reanalyses.

\begin{tabular}{l}
\hline Dataset(institution) \\
\hline Twentieth Century Reanalysis (20CRv3) \\
[National Oceanic and Atmospheric \\
Admin. (NOAA), Cooperative \\
Institute for Research in \\
Environmental Sciences (CIRES), and \\
Department of Energy (DOE)]
\end{tabular}

JRA-55 [Japan Meteorological Agency (JMA)]

\section{CERA-20C (ECMWF)}

\section{ERA5 (ECMWF)}

MERRA-2 [National Aeronautics and Space Administration (NASA) Global Modeling and Assimilation Office (GMAO)]

General reanalysis characteristics

1836-2015 record; uses 2017 NCEP GFS assimilation model, $\sim 0.7^{\circ}$ grid resolution, 80-member ensemble

Kalman filter with 4D incremental analysis update (Bloom et al. 1996; Lei and Whitaker 2016)

Assimilates International Surface

Pressure Databank v4.7

1981-2015 HadISST2.2 SSTs, (Rayner

et al. 2006; Slivinski et al. 2019)

1836-1980 SODAsi.3 SSTs (Giese et al. 2016)

1973-2012 record; uses 2009 JMA semiLagrangian, 4D-Var, operational model ( $\sim 55-\mathrm{km}$ grid resolution); COBE SST (Ishii et al. 2005)

Extensive conventional upper-air, satellite, aircraft, ship, and in situ observations assimilated; JRA-55C (1973-2012) Note: JRA-55C assimilated conventional observations only.

1901-2010 record; 10-member ensemble integrations of CY41R2 of ECMWF Integrated Forecast System; 125-km atmosphere grid resolution (110$\mathrm{km}$ ocean).

$P_{s}$ and marine wind observations are assimilated in the atmospheric model, from the ISPDv3.2.6 (Cram et al. 2015) and ICOADSv2.5.1 (Woodruff et al. 2011)

SST relaxed to HadISST2 monthly ensemble product (Titchner and Rayner 2014); ocean subsurface $T$ and salinity from bias-corrected EN4.0.2 dataset (Good et al. 2019)

1950-present; 31-km grid resolution; hourly archival; Integrated Forecasting System (IFS) Cy41r2.31; model 12-h window for 0000, 1200 UTC 4D-Var Assimilation.

Extensive conventional upper-air, satellite, aircraft, ship, and in situ observations assimilated

SST/sea ice from HadISST2 through Aug 2007, OSTIA from September 2007 to present (Hirahara et al. 2016)

GEOS version 5.12.4 uses 3D-Var atmospheric data assimilation system with 6-h incremental analysis update; $0.5^{\circ} \times 0.625^{\circ}, 72$ level grid, available from 1980 to present.

Extensive conventional upper-air, satellite, aircraft, ship, and in situ observations assimilated

Reynolds et al. (2007) SST with OSTIA (Donlon et al. 2012) after 2006
Dataset availability and documentation

https://www.esrl.noaa.gov/psd/data/ 20thC_Rean/

Compo et al. (2011)

Slivinski et al. (2019)

https://jra.kishou.go.jp/JRA-55/

Kobayashi et al. (2014)

Kobayashi et al. (2015)

https://www.ecmwf.int/en/forecasts/ datasets/reanalysis-datasets/era5

Laloyaux et al. (2016)

Laloyaux et al. (2018)

https://cds.climate.copernicus.eu/ cdsapp\#!/dataset/reanalysis-era5single-levels-monthly-means? $\mathrm{tab}=$ overview

Hersbach et al. 2020

https://disc.gsfc.nasa.gov/MERRA-2

Gelaro et al. (2017)

Bosilovich et al. (2017) 
The $Q_{a}$ estimates use as predictors not only SSM/I Tb but also ERA-Interim (ERA-I) SST and 2-m temperature $\left(T_{2 \mathrm{~m}}\right) / \mathrm{SST}$ stratification. Coefficients of this empirical relationship are determined through a maximum likelihood method using ICOADS v3 data and ERA-I SST and $10-\mathrm{m}$ temperature (T10m). Spatially and temporally dense ERA-I reanalysis $Q_{a}$ data are used as an external constraint applied on a daily basis to the temporally sparser satellite retrievals. The 2-m ERA-I and ICOADS data are adjusted to $10-\mathrm{m}$ levels using the COARE 3.0 algorithm (Fairall et al. 2003). Wind speeds are a combination of scatterometer and RSS radiometer retrievals (Bentamy et al. 2017). Turbulent fluxes are estimated using the COARE 3.0 algorithm with SST estimates from OISST AVHRR-only (hereafter OISST-A; Reynolds et al. 2007) and the above described winds, near-surface humidity, and temperature.

\section{2) J-OFURO3}

The latest update to the J-OFURO datasets, J-OFURO3. 1.1 (hereafter JOFURO3; Tomita et al. 2019), offers a broad array of surface turbulent, freshwater, and radiative flux components and employs virtually all available satellite-borne microwave radiometers and scatterometers. RSS V7.1 brightness temperatures constitute the FCDR. To develop the $Q_{a}$ algorithm, columnintegrated water vapor $W$ from retrievals by Wentz et al. (2013), surface air density, $\rho_{a}=1.2 \mathrm{~kg} \mathrm{~m}^{-3}$, and ERA-I $Q_{a}$ are used to define the water vapor scale height, $H_{v}=$ $W /\left(\rho_{a} Q_{a}\right)$, over six different categories with differing moisture stratification regimes (Tomita et al. 2018). The term $H_{v}$ is then used in conjunction with ICOADS V $3 Q_{a}$ and RSS brightness temperatures to train a $Q_{a}$ retrieval algorithm for each $H_{v}$ category. The $Q_{a}$ retrievals are subsequently intercalibrated relative to F13. Surface wind speed retrievals blend RSS v7 passive microwave products as well as Centre ERS d'Archivage et de Traitement (CERSAT) scatterometer retrievals from ERS-1 and ERS-2, QuikSCAT, ASCAT-A and ASCAT-B, and OceanSat Scatterometer (OSCAT) produced by NASA JPL. A new ensemble median SST (EMSST) product has also been produced that blends 12 different SST analyses.

\section{3) HOAPS-4}

Intercalibrated and homogenized SSM/I and SSMIS $\mathrm{Tb}$ values from the EUMETSAT Climate Monitoring Satellite Applications Facility FCDR (Fennig et al. 2015, 2020) comprise the fundamental Level 1 input for Hamburg Ocean Atmosphere Parameters and Fluxes from Satellite Data version 4 (HOAPS-4) estimates (hereafter HOAPS4). Among others, turbulent and freshwater fluxes over the ice-free global oceans from
July 1987 through 2014 are estimated with the COARE 2.6a bulk aerodynamic algorithm (Fairall et al. 1996, 2003; Andersson et al. 2010). Six-hourly composites and monthly averages are available on a global $0.5^{\circ} \times 0.5^{\circ}$ latitude/longitude grid. Near-surface 2-m specific humidity retrievals use the Bentamy et al. (2003) algorithm. The 10-m neutral surface wind speed and vertically integrated water vapor are retrieved via an updated Numerical Weather Prediction Satellite Applications Facility 1D-Var routine. Radiative transfer modeling of $\mathrm{Tb}$ for channel-specific wavelengths based on atmospheric background fields (13000 over ocean) uses a predefined 91-level atmospheric profile database constructed from ECMWF short-range forecasts (Chevallier et al. 2006). NOAA $0.25^{\circ}$ daily OISST-A, version 2 (Reynolds et al. 2007; Reynolds 2009), is used as input with a skin temperature estimate following Donlon et al. (2002).

\section{4) SEAFLUX-V3}

Multiple improvements have been made to the SeaFlux-CDR, termed SeaFlux-V3 (hereafter SeaFluxV3; Roberts et al. 2020). These estimates have been developed using the latest Global Precipitation Measurement Mission Level 1C Intercalibrated brightness temperature record (Berg et al. 2018). The nonlinear neural network (NN)-based retrievals of wind speed, air temperature, and air specific humidity (Roberts et al. 2010) were updated to include a priori estimates of water vapor stratification and the surface to $850-\mathrm{hPa}$ mean layer temperature from MERRA-2 to address the regional biases found in Roberts et al. (2020); like JOFURO3 this approach tries to accommodate variable water vapor stratification. A total of 14 available microwave imagers are used including SSM/I, SSMIS, TMI, AMSR-E, AMSR-2, and GMI. Near-surface LHF estimates from each sensor were further intercalibrated using collocated estimates; the intercalibration was chained backward in time using GMI as the primary reference. Diurnally varying sea surface temperatures generated for the SeaFlux-CDR record were applied to the OISST-A for all surface flux computations using the COARE-3.5 (Edson et al. 2013) algorithm.

\section{5) OAFLuXv3}

Monthly Objectively Analyzed Air-Sea Fluxes version 3 data (OAFluxV3; Yu and Weller 2007; Jin et al. 2015) goes beyond using just satellite-derived near-surface meteorology (Jackson et al. 2009; Shie et al. 2012); it also takes these quantities from reanalyses and blends these using objective analysis constraints. The COARE 3.0 algorithm synthesizes fluxes from these input fields and OISST-A (Reynolds et al. 2007). Because distinguishing 
the influence of satellite versus reanalysis input sources on the variability within this dataset is difficult, we show OAFluxV3 time series for comparison purposes without further analysis.

\section{b. RedObs}

Since high-resolution gridded validation data at monthly to interannual scales are essentially nonexistent, we appeal to three reanalyses that have no assimilation of satellite atmospheric moisture or temperature data (RedObs). As discussed earlier these integrations are not regarded as validation but are informative because they are not subject to uncertainties stemming from discrete changes in satellite data assimilation, particularly that of atmospheric moisture. Details of these three reanalysis datasets- the ECMWF coupled ERA twentieth century integration (Laloyaux et al. 2018), the NOAA-CIRES-DOE Twentieth Century Reanalysis, V3 (Compo et al. 2011; Slivinski et al. 2019), and the Japanese Meteorological Agency JRA-55C (Kobayashi et al. 2014, 2015) - are provided in Table 2. These datasets (hereafter CERA20C, 20CRv3, and JRA55C) extend through 2010, 2015, and 2012, respectively. Their suite of assimilated observations differs between ingesting surface pressure and marine wind speed (CERA20C), only surface pressure (20CRv3), or all nonsatellite data (JRA55C). To produce an ensemble, we first deseasonalized each of the RedObs around the respective monthly climatologies defined over the 1992-2010 period and then averaged these anomalies. Because the datasets end at different times between 2010 and 2015, this insures that interannual and longer signals are not confounded with any offsets in climatological amplitudes.

For comparison to the RedObs and satellite LHF estimates we focus on the ECMWF reanalysis, ERA5 (Hersbach et al. 2020), the newest comprehensive system assimilating extensive conventional and satellite data records (see also Table 2).

\section{c. Supporting ancillary data}

Another estimate of LHF can be constructed as a residual in the atmospheric moisture budget:

$$
\mathrm{LHF}=L_{v} \rho_{o}[\operatorname{Div}(q V)+P+d W / d t],
$$

where reanalysis ${ }^{3}$ vertically integrated moisture flux divergence, $\operatorname{Div}(q V)$, and storage $d W / d t$ are combined

\footnotetext{
${ }^{3}$ Reanalyses contain an additional term $L_{v} \rho_{o}\left(Q_{\text {ana }}\right)$ on the righthand side of (2) containing moisture increments necessary to preserve a closed budget in the face of reconciling model physics and assimilated observations. Since (2) does not directly involve model physics this term is absent.
}

with satellite $P$. Brown and Kummerow (2014) have used this approach to study regional tropical moisture budget behavior using GEWEX flux products. In reanalyses, $\operatorname{Div}(q V)$ is generally regarded as more accurate than $E-P$ since the former is strongly influenced by observed, assimilated state variables whereas $E$ and $P$ are products of model physics (Trenberth and Guillemot 1998; Trenberth et al. 2011). The moisture flux divergence $\operatorname{Div}(q V)$, from the ERA5, JRA-55, and MERRA-2 reanalyses (see also Table 2) is combined with two satellite precipitation datasets to infer ocean LHF for evaluating the RedObs and satellite-based estimates. GPCP v2.3 precipitation (Adler et al. 2017, 2018) is a widely used benchmark for climate studies. For comparison, RSS V7 SSM/I, SSMIS, AMSR-E, and WindSat precipitation retrievals (Hilburn and Wentz 2008; Wentz 2015) are also used. We intercalibrated $P$ retrievals from these individual sensors to that of SSM/I F13 using a zonal mean, multiplicative rescaling averaged during sensor overlap periods. Averaged latitudinally, these adjustments were on the order of $1 \%-$ $2 \%$ at most. The $d W / d t$ constructed from centered monthly differences of ERA5 $W$ is found to be vanishingly small on global-ocean scales compared to the other terms. As added context for the RedObs, a fivemember LHF ensemble was made using AMIP6 integrations from five randomly selected modeling groups (Table 3). Experiment members were downloaded from https://esgf-node.llnl.gov/search/cmip6/.

To aid in interpreting how wind speed uncertainties affect LHF estimates from satellites and reanalyses, we use 10-m neutral wind speed retrievals from the RSS V7 collection encompassing individual SSM/I and SSMIS, QuikSCAT, WindSat, and Advanced Scatterometer on MetOp-A (ASCAT-A) sensors. These retrievals are unbiased versus global buoys, with an uncertainty of about $0.1 \mathrm{~m} \mathrm{~s}^{-1}$ for global monthly averages. Details of these retrievals are found in Wentz (2013, 2015), Ricciardulli and Wentz (2015), and Wentz et al. (2017). Additional documentation and data access are available at www.remss.com.

Because $Q_{s}(\mathrm{SST})$ plays a fundamental role in bulk aerodynamic estimates of turbulent fluxes analyses, we examine a number of SST datasets in addition to those associated with the reanalysis and the satellite estimates. Chief among these are SSTs from the European Space Agency Sea Surface Temperature Climate Change Initiative (ESA SST CCI; Merchant et al. 2014, 2019). The Along Track Scanning Radiometer (ATSR) and Advanced ATSR (AATSR) instruments provide skin temperature measurements with consistently small SST biases (Embury et al. 2012; Merchant et al. 2012, 2019) and significant reduction of aerosol effects compared to 
TABLE 3. AMIP6 experiments used in making a five-member ensemble used in this study.

\begin{tabular}{lc}
\hline \multicolumn{1}{c}{ Institution } & Experiment member \\
\hline NCAR CESM2 (National & hfls_Amon_CESM2_amip-hist_ \\
Center for Atmospheric & r3i1p1f1_gn_197001- \\
Research Community Earth & 201412.nc \\
System Model 2) & \\
CNRM-CERFACS (Centre & hfls_Amon_CNRM-CM6-1_ \\
National de Recherches & amip-hist_r10i1p1f2_gr_ \\
Météorologiques-Centre & 187001-201412.nc \\
Européen de Recherche et de & \\
Formation Avancée en Calcul & \\
Scientifique) & \\
CAMS-CSM1 (Chinese & hfls_Amon_CAMS-CSM1-0_ \\
Academy of Meteorological & amip-hist_r2i1p1f1_gn_ \\
Sciences Climate System & 187001-201412.nc \\
Model 1) & \\
MIROC6 (Japan Agency for & hfls_Amon_MIROC6_amip- \\
Marine-Earth Science and & hist_r4i1p1f1_gn_197001-201 \\
Technology. Model for & \\
Interdisciplinary Research on & \\
Climate) & \\
IPSL (Institute Pierre Simon & hfls_Amon_IPSL-CM6A-LR_- \\
Laplace) & amip-hist_r3i1p1f1_gr_ \\
& 187001-201412.nc \\
\hline
\end{tabular}

other single-angle viewing sensors. The retrievals rely on line-by-line radiative transfer modeling and are also essentially independent of any in situ SST measurements. While available from October 1991 through October 2010, there are a number of data gaps (AprilJune 1996 and most of January-February 2001). ESA CCI has used an optimum interpolation methodology to calibrate AVHRR data to the ASTR record providing a 20-cm depth, level-4 product, ESA SST CCI v2.1 (Good et al. 2019), that extends through 2016. The stability of the global SST relative to drifting buoys is within $0.003 \mathrm{~K} \mathrm{yr}^{-1}$ (Merchant et al. 2019). We use this as a benchmark for judging other SST and $Q s(\mathrm{SST})$ records and how they affect LHF estimates and reanalyses. For comparison we also examine the SST records of COBE2 (Hirahara et al. 2014) and ERSST-5 (Huang et al. 2017), which are datasets of SST from in situ sensors, interpolated using different methods.

\section{Intercomparison of LHF anomalies}

\section{a. Globally averaged time series}

Near-global $\left(60^{\circ} \mathrm{N} / \mathrm{S}\right.$ area-weighted average) anomalies, constructed as described in section 2 from the four LHF estimates, RedObs, and the ERA5 reanalysis are shown in Fig. 1a and for the individual RedObs in Fig. 1b. For display purposes a 3-month running mean filter has been applied. Immediately apparent is the contrast in trends and decadal-scale variability among the satellite estimates and the smaller trends for the RedObs. Note also the relatively small size of all anomalies compared to the climatological means and their diversity (side panels in Fig. 1). Low-frequency behavior and decadal-scale trends are much greater in IFREMER4 and HOAPS4 with JOFURO3 and SeaFluxV3 somewhat closer to the RedObs. ERA5, the most recent and comprehensive reanalysis, has a smaller increase than IFREMER4 and HOAPS4 during the post-2000 era, but when considering the period back to 1980 , also has a much larger trend than the RedObs. The contrast of this trend with that of the CERA20C RedObs member, which uses a closely related atmospheric model and assimilation system, motivates us to consider temporal differences in near-surface wind speed and $Q_{a}$ behavior with time which we examine in section 4. OAFluxV3 trends upward strongly before 2000 but then decreases strongly thereafter. The spread in trends over the period 1990-2010 among satellite estimates themselves is substantial and larger than each of the RedObs (Fig. 1b). The smaller RedObs trend is not due to averaging out "noise" or differences among the three individual members. Although CERA20C and 20CRv3 time series themselves are each an ensemble average there is strong coherence between the three individual RedObs time series. An ensemble mean of five AMIP6 experiments (Table 3) similarly indicates little or no multidecadal trend yet shows noticeably reduced-amplitude interannual signals. This reduction comes largely from the damping of each member's different internal atmospheric variability by the ensemble averaging and illustrates the difference between the AMIP simulations and RedObs reanalyses.

A further assessment of the diversity in decadal-scale variability among the satellite-based estimates and RedObs LHF comes from the budget residual estimate in Eq. (2). The $\operatorname{Div}(q V)$ anomalies from the three fullinput reanalyses (Fig. 2a) show consistent variability with global ocean moisture convergence (divergence) slightly leading ENSO warm (cold) events. Multidecadalscale trends are small compared to the much larger monthly to interannual signals and are not significant at the $90 \%$ level. Global ocean precipitation time series (Fig. 2b) from GPCP (Adler et al. 2017, 2018) and RSS (Hilburn and Wentz 2008; Wentz 2015) show consistency with large interannual variability and small, uncertain trends.

LHF anomalies estimated from (2) are shown in Fig. $2 c$ along with those of the RedObs ensemble mean and JOFURO3. Like the RedObs, the budget residualbased LHF calculations using each of the two $P$ estimates clearly have very small decadal trends and agree 


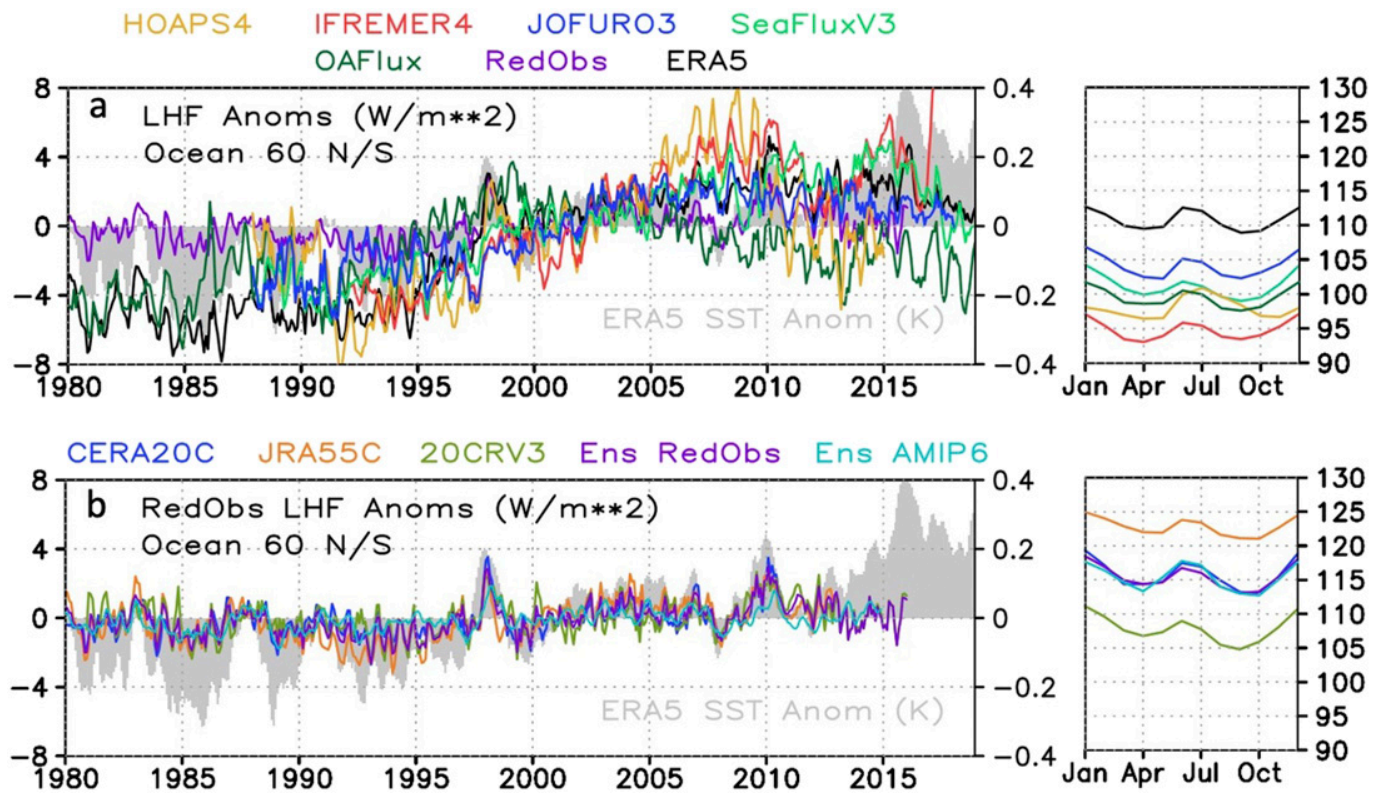

FIG. 1. (a) Time series of area-averaged ocean latent heat flux anomalies ( $\mathrm{W} \mathrm{m}^{-2}$; left axis) over $60^{\circ} \mathrm{N} / \mathrm{S}$. Base climatology is 1992-2010. (b) As in (a), but for individual RedObs and the ensemble RedObs and AMIP6 ensemble means. Anomalies are departures from monthly resolved, 1992-2010 climatologies; the latter are shown in the right panels. Solid gray shading is SST anomaly ( $K$; right axis). A 3-month running mean filter has been applied to each anomaly time series.

reasonably well on interannual time scales (e.g., the $1997 / 98$ and 2009/10 El Niño events). This level of agreement is noteworthy given that any residual method potentially suffers from error accumulation by the contributing terms. JOFURO3 exhibits larger negative values over the 1990s and thus a larger decadal-scale trend. Comparing Figs. 2c and 1a shows that the other three satellite LHF estimates have similar or even larger decadal variations than JOFURO3. To first order $\operatorname{Div}(q V)$ and $P$ are independent of the satellite LHF estimates. Although reanalyses assimilate passive microwave radiances and near-surface wind retrievals, the $\operatorname{Div}(q V)$ data are short-term forecasts from the reanalyses. GPCP and RSS $P$ retrievals depend on passive microwave emission signatures by liquid water whereas satellite $Q_{a}$ and wind speed retrievals are only made in non-raining sensor footprints.

Several important points should be noted here. Despite the agreement between reanalysis and RedObs LHF trends at global ocean scale, patterns of these trends appear distorted at regional and local scales in the reanalyses, particularly in the tropical Western Hemisphere (not shown). This is likely due in part to the fact that the $\operatorname{Div}(q V)$ results here have not yet been corrected for atmospheric mass balance (Trenberth 1991; Trenberth and Fasullo 2018; Mayer et al. 2017) as is necessary for far more sensitive energy budget calculations. However, the close agreement of the three independent reanalyses and with RedObs (Fig. 2) suggests that at these near-global scales wind component corrections to ensure mass balance do not significantly alter $\operatorname{Div}(q V)$ time series. Furthermore, preliminary work (not shown) examining $E-P$ from observationally constrained land surface models and, thus, implied moisture exchange with ocean areas, also strongly confirms the reanalysis global ocean $\operatorname{Div}(q V)$ variability in Fig. 2a. These results justify interpreting the budget residual-based LHF estimates as evidence for the utility of the RedObs and strongly suggest that current larger decadal trends in the satellite LHF retrievals are exaggerated to varying degrees.

Comparing the amplitude of the LHF global mean excursions to the respective climatological amplitudes (side panels in Figs. 1a,b) reveals that seasonal to interannual variability is on the order of $2 \%-3 \%$. But over the 20 -yr period beginning in 1990 , some satellite estimates increase by as much as $5 \%-10 \%$, as does ERA5, which is anomalously low before that time. During this period global SST has increased about $0.13 \mathrm{~K} \mathrm{decade}^{-1}$. Consistent with scaling arguments alluded to earlier (Allen and Ingram 2002; Held and Soden 2006) one would expect trends near $0.26 \mathrm{~W} \mathrm{~m}^{-2} \mathrm{decade}^{-1}\left(\sim 100 \mathrm{~W} \mathrm{~m}^{-2} \times\right.$ $\left.0.13 \mathrm{~K} \mathrm{decade}^{-1} \times 0.02 \mathrm{~K}^{-1}\right)$, or about $0.5 \mathrm{~W} \mathrm{~m}^{-2}$ over this 20 -yr period for purely externally driven radiative effects. However, this estimate is based on an equilibrium response and neglects possible higher-frequency variations 

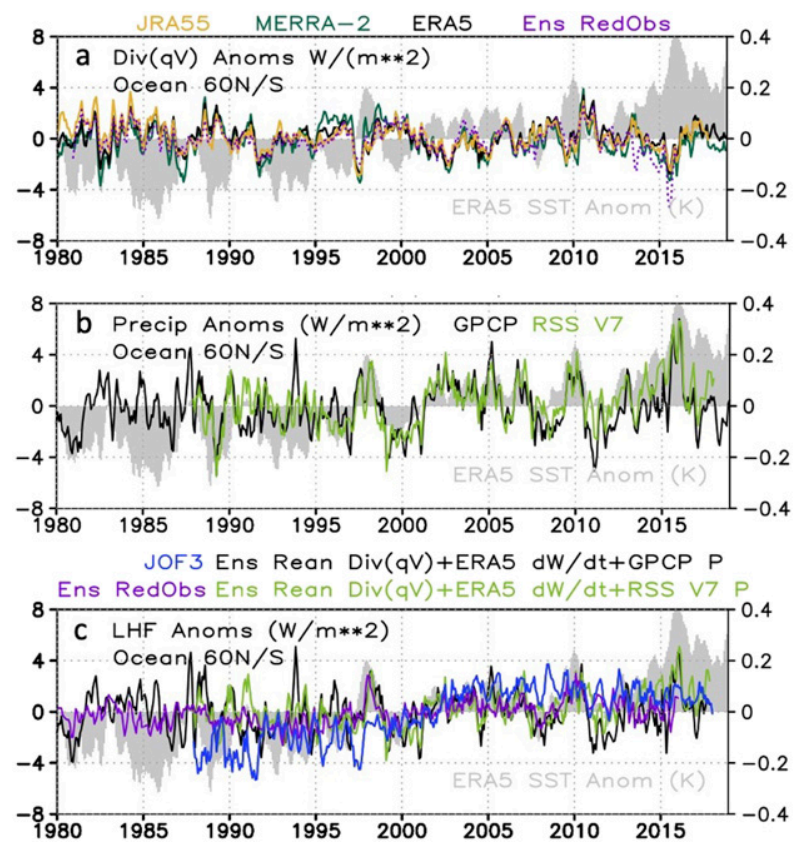

FIG. 2. (a) Anomalies of vertically integrated moisture flux divergence $\operatorname{Div}(q V)$ from three reanalyses and the three member RedObs ensemble area-averaged over the global oceans, $60^{\circ} \mathrm{N} / \mathrm{S}$ $\left(\mathrm{W} \mathrm{m}^{-2}\right.$ ). (b) As in (a), but for two precipitation datasets. (c) LHF anomalies calculated as a residual in the atmospheric moisture budget [Eq. (2)] using the ensemble reanalysis $\operatorname{Div}(q V)+$ ERA $5 d W / d t+$ either of the two $P$ estimates in (b). Also shown are JOFURO3 and RedObs LHF anomalies. See section $2 \mathrm{c}$ in text for details. A 3-month running mean filter has been applied to each anomaly time series.

due to natural climate variability. All of the satellite estimates in Fig. 1a exhibit LHF increases more than an order of magnitude larger than $0.5 \mathrm{~W} \mathrm{~m}^{-2}$. The RedObs and residual-diagnosed LHF changes over this period are systematically much smaller but still larger spanning the period roughly 1990-2010 than scaling estimates from external forcing alone. There are at least two possible explanations for these differences. Given the spread of satellite retrieval trends, there are errors that most likely trace back to the input near-surface moisture and wind data driving the COARE flux algorithm. But by selecting the period spanning 1990-2010 we also capture a number of ENSO events and a large change in IPO signals (Zhang et al. 1997; Power et al. 1999; England et al. 2014). Variability induced by these climate modes could produce LHF anomalies that partially explain the larger trends.

\section{b. Signal-to-noise structure}

Examining maps of signal-to-noise $(S / N)$ for the LHF estimates and for the RedObs provides a basic metric of agreement between datasets on temporal variability at the grid point scale. The signal $\overline{\sigma_{n}}$ at any grid location is the temporal average standard deviation of the ensemble mean anomalies from their respective climatologies. The noise $\overline{s_{n}}$ is the temporal average standard deviation of the anomalies around their ensemble mean $\bar{x}$; that is,

$$
S / N=\overline{\sigma_{n}} / \overline{s_{n}}=\sqrt{\frac{1}{\sum_{i=1}^{n} x_{i}^{2}}} / \sqrt{\sqrt{\frac{1}{n} \sum_{i=1}^{n}\left(x_{i}-\bar{x}\right)^{2}}},
$$

where $x$ denotes anomalies with respect to the 1992 2010 climatology for each of the " $n=4$ " retrieval estimates (or three reanalyses), $\bar{x}$ is the ensemble mean anomaly, and the bar indicates averaging over the period 1992-2010.

Satellite LHF $S / N$ maxima (Fig. 3a) exceed 4.0 in the North Atlantic with weaker maxima east of Japan where storm tracks originate over poleward western boundary currents. Other maxima are located over the Southern Ocean, poleward of the SPCZ, and also in the tropical eastern Pacific associated with ENSO variance. RedObs $S / N$ strength is systematically smaller over most of the global oceans with values as low as 1.0 in the IndoPacific region. An exception is in the eastern basin regions of the $\mathrm{NH}$ extratropics where values exceed 5. This is likely due to the high density of marine data available for assimilation.

Wind speed $S / N$ amplitudes contrast vividly between the satellite estimates and the RedObs (Figs. 3c,d). Retrieval maxima near 5.0 dominate the equatorial date line region with smaller values extending eastward. Pronounced minima (maxima) in wind speeds are found here in conjunction with El Niño (La Niña) events (Bjerknes 1969). TAO buoy array $Q_{a}$ and wind speed strongly constrain most of the estimates when used as algorithm training data and affect data assimilation as well. Agreement also runs in a diagonal region southwestward over Hawaii. A similar band of maxima extends northwestward along the equatorward reaches of the southeast Pacific anticyclone (Zhang et al. 2014). Other smaller $S / N$ maxima found in the subtropical Atlantic, again likely in conjunction with ENSO-related variations of inflow to the Amazon basin. In contrast the RedObs show much weaker $S / N$ values in the tropics as a whole although the pattern structure is somewhat similar-relative maxima over the equatorial date line, in the periphery of the SH eastern Pacific anticyclone, and (weakly) in the NH subtropics. Much more pronounced $S / N$ maxima are found in the eastern extremities of NH storm tracks, consistent with the LHF $S / N$ maxima. Radiometer wind speed retrievals are input common to all satellite LHF estimates and may explain their higher $S / N$. In the case of RedObs, assimilated wind observations in CERA-20C and JRA55C are not 
Satellite Retrievals
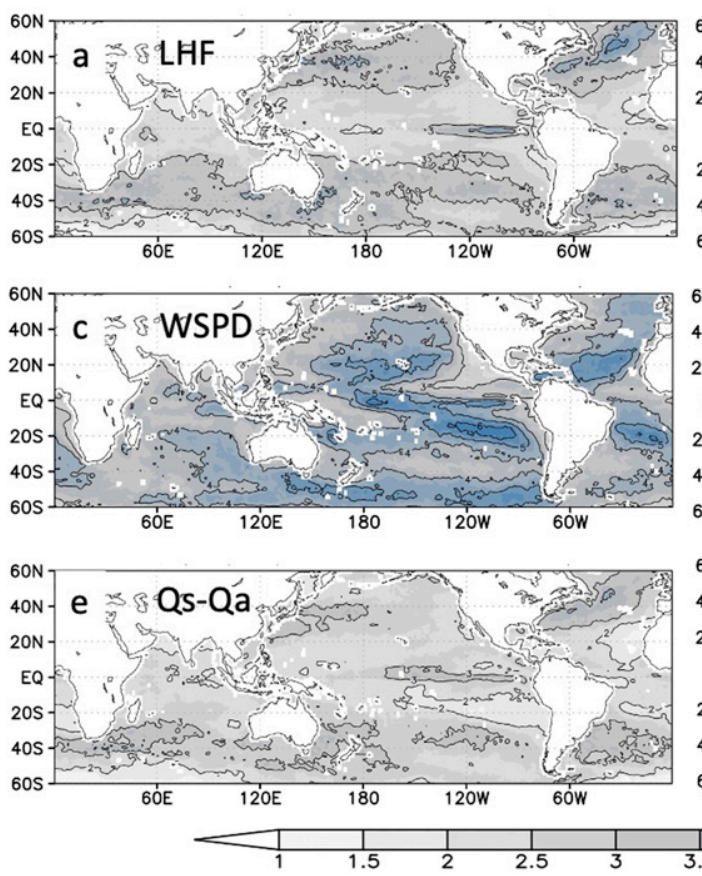
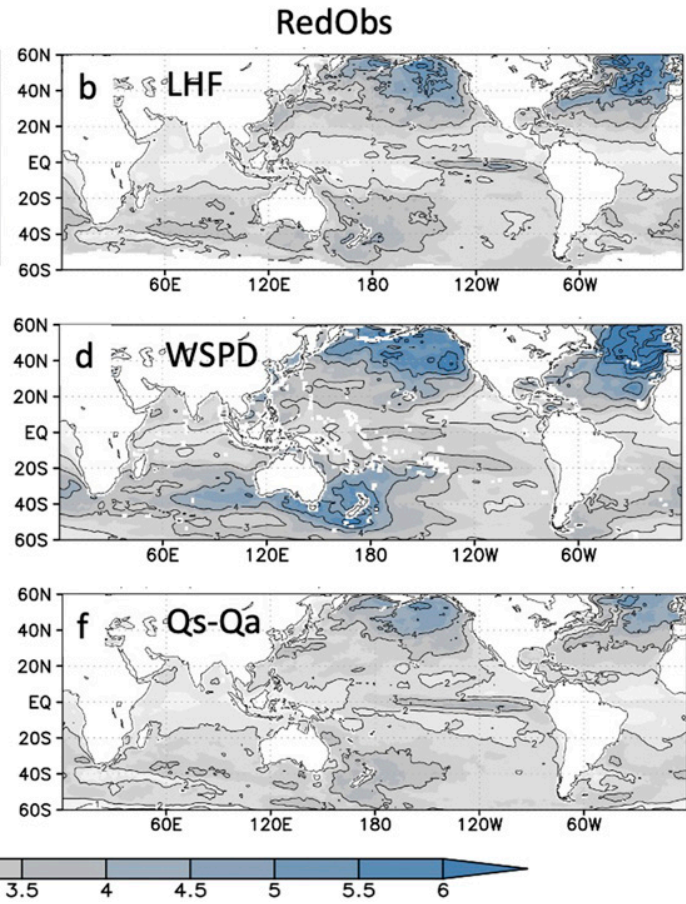

FIG. 3. Signal-to-noise $(S / N)$ maps of LHF, 10-m wind speed, and $Q_{s}-Q_{a}$ for satellite retrievals and RedObs using data over 1992-2010 period. The signal at any grid location is the temporal average standard deviation of the ensemble mean anomalies from their respective climatologies. The noise is the temporal average standard deviation of the anomalies around the ensemble mean of the anomalies.

dense over the tropics as a whole and are not used at all in 20CRv3. Large-scale pressure gradient changes are linked to large-scale flow structures on the interannual to decadal scales of interest here (Vecchi et al. 2006), but not the details of synoptic-scale systems that the gridpoint $S / N$ diagnostic measures.

For both the satellite and RedObs, $Q_{s}$ and $Q_{a} S / N$ patterns and amplitudes (Figs. 3e,f) are much more similar to the LHF patterns than they are to the wind speed patterns with maxima found in extratropical storm tracks and in the equatorial eastern Pacific.

\section{Variability and consistency of bulk variables}

In this section we pursue the origin of these differences among LHF estimates and, where possible, identify error sources in the near-surface meteorological inputs.

\section{a. Wind speed}

Near-surface wind speed anomaly time series over the global oceans are given in Fig. 4a with the individual RedObs time series in Fig. 4b. Peak interannual and decadal extrema are on the order of $0.1-0.2 \mathrm{~m} \mathrm{~s}^{-1}$ corresponding to roughly $3 \%-5 \%$ or less of global means (not shown). Interannual wind speed anomalies associated with large El Niño events (1997/98, 2009/10, 2015/16) show a characteristic drop prior to global SST maxima and then change to positive values as the events mature and subside. This behavior is a signature of weakening easterlies along the equatorial central Pacific followed by their resurgence as cold equatorial water and increased west to east pressure gradients strengthen again. Over a longer period from the early 1990 s to nearly 2010 , wind speeds increase for all datasets consistent with the increasingly negative IPO index (de Boisséson 2014; England et al. 2014). There is also an emerging reversal of this upward wind speed trend after 2010 shared by the satellite estimates and the RedObs.

Several instances of disagreement among the time series are notable in Fig. 4. JOFURO3 has positive anomalies in the late 1987-90 period, during the tenure of SSM/I F08. The single satellite F08 coverage and its lone year overlap with $F 10$, which has an anomalously eccentric orbit with temporally drifting equatorial crossing times, increases uncertainties early in the record. The 1991/92 El Niño, which should favor wind speed reductions followed by increases during this period, further complicates intersensor calibration. Wentz (2013) document suspiciously low $37-\mathrm{GHz}$ antenna temperatures and resulting wind speeds in the first two years for F11, which they address by modifying the antenna 


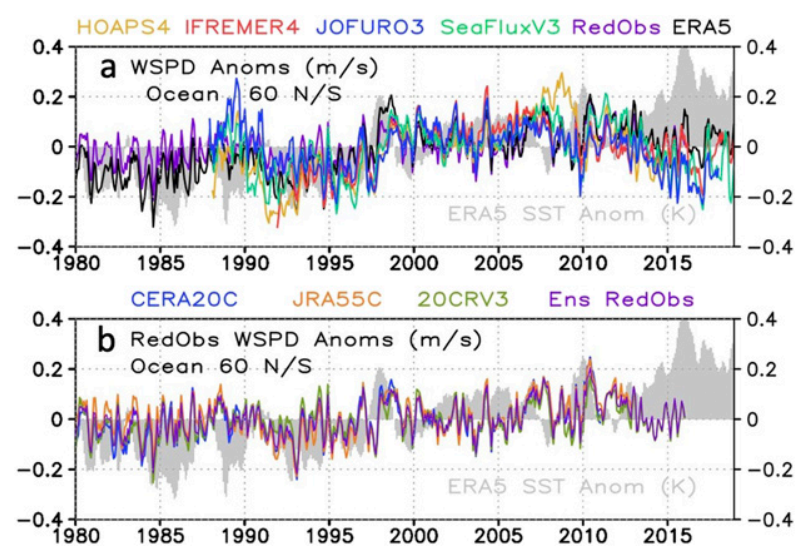

FIG. 4. Global average $\left(60^{\circ} \mathrm{N} / \mathrm{S}\right) 10-\mathrm{m}$ wind speed anomalies. Colors as noted in the legend. Gray shading is global ERA5 SST anomalies ( $K$; right axis). A 3 -month running smoother has been applied to each time series.

temperature at $37 \mathrm{GHz}$ during this period (Wentz 2013). However, this issue is not noted in any of the other FCDRs. Although the GPM Level 1C documentation does not explicitly identify any drift with the first two years of F11, SeaFluxV3 documentation (Roberts et al. 2020) ignores the first two years of $F 11$ in developing post-retrieval intercalibration of the individual sensors but subsequently weights these data low in subsequent averaging of the sensor estimates.

HOAPS4 exhibits outlier wind speeds in 2008/09. After 2009, SSM/I F13 coverage ends and only SSMIS sensors continue ( $F 16, F 17$, and $F 18$, respectively). Despite having the same window channel frequencies, they differ from the SSM/I sensors in important engineering aspects. Adjustments in FCDR brightness temperatures (Berg and Sapiano 2013; Wentz 2013; Fennig et al. 2015, 2020) for an emissive antenna, the occurrence of solar and lunar intrusions into the warm and cold calibration loads, and an obstruction within limb fields of view (Bell et al. 2008; Swadley et al. 2008) are more severe than for the SSM/I sensors.

To examine SSMIS wind speed retrievals more closely, the individual SSMIS wind speed retrievals available from HOAPS4, SeaFluxV3, and RSS V7 were differenced from the more stable RSS WindSat retrievals (Wentz 2015) spanning the SSMIS record (Fig. 5). Even after adjustments to FCDR brightness temperatures, all retrievals show evidence of suspicious annual cycles and/ or temporal changes in the resulting wind speed record. Retrievals based on F16 (Fig. 5a) show decreases in time of $0.25-0.5 \mathrm{~m} \mathrm{~s}^{-1}$ compared to WindSat, with HOAPS4 and RSS having the steepest trends and SeaFluxV3 having the smallest. These trends may bear some relationship to the F16 precession through the diurnal cycle since trends for retrievals based on F17, which does not precess, are much smaller (Fig. 5b). It is possible that the sensor calibration issues mentioned earlier (e.g., solar and lunar intrusions into sensor feedhorns, or antenna emissivity) may vary according to differing sensor orientation with respect to the sun in ways not yet understood. Wind speeds from $F 18$, whose equator crossing time also precesses, exhibit a change in annual cycle with time compared to the nonprecessing WindSat. The SeaFluxV3 wind speeds based on $F 18$ also have an especially pronounced downward trend and amplifying annual cycle compared to those based on WindSat (Fig. 5c). Differences between WindSat and other independent sensors including RSS ASCAT-A and SeaFluxV3 TMI and GPM as well as RedObs indicate that each of these wind speed records has very little temporal drift compared to WindSat. The low bias in the SeaFluxV3 TMI and GMI retrievals compared to RSS WindSat (Fig. 5d) largely reflects SeaFluxV3's retrieval of actual 10-m wind speeds compared to RSS neutral stability values (Roberts et al. 2020).

Finally, ERA5 and RedObs global mean wind speeds agree well (Fig. 4) on interannual scales. However, an examination of their differences suggests that ERA5 wind speeds increase systematically by about 0.10 $0.15 \mathrm{~m} \mathrm{~s}^{-1}$ between 1995 and 1998 and equilibrate to a difference of $\sim 0.07 \mathrm{~m} \mathrm{~s}^{-1}$ with the RedObs by 2010 (Fig. 6a). This increase is focused in the tropical Pacific with two centers of positive increases straddling the equator (Fig. 6b, and gray curve in Fig. 6a) and is partly responsible for the upward ERA5 LHF trend seen in Fig. 1. The sudden increase in the amount of SSM/I wind data available during the mid-1990s, particularly the addition of $F 13$ in early 1995, may drive this sudden change. Another factor with potential impact is the assimilation of scatterometer data from ERS-1 and ERS-2 in 1991 and 1995, respectively. Complicating any interpretation is the strong 1997/98 El Niño and subsequent cool period; however in testing a variety of different periods to make the difference plot, very little pattern change was noted. We suspect that this pattern reflects a different intensity with which the SSM/I and scatterometer (e.g., ERS-1 and ERS-2, QuikSCAT) sensors detect the "hiatus"-related wind speed changes compared to that which the atmospheric model used in ERA5 would produce if run with no satellite-derived near-surface wind assimilation.

\section{b. Water vapor deficit (or gradient) $Q_{s}-Q_{a}$}

In this section we examine the behavior of satelliteretrieved $Q_{s}-Q_{a}$ as well as $Q_{a}$ and $Q_{s}$ separately. Comparisons to RedObs are also made since they have no input of satellite moisture data. The distinct trend 


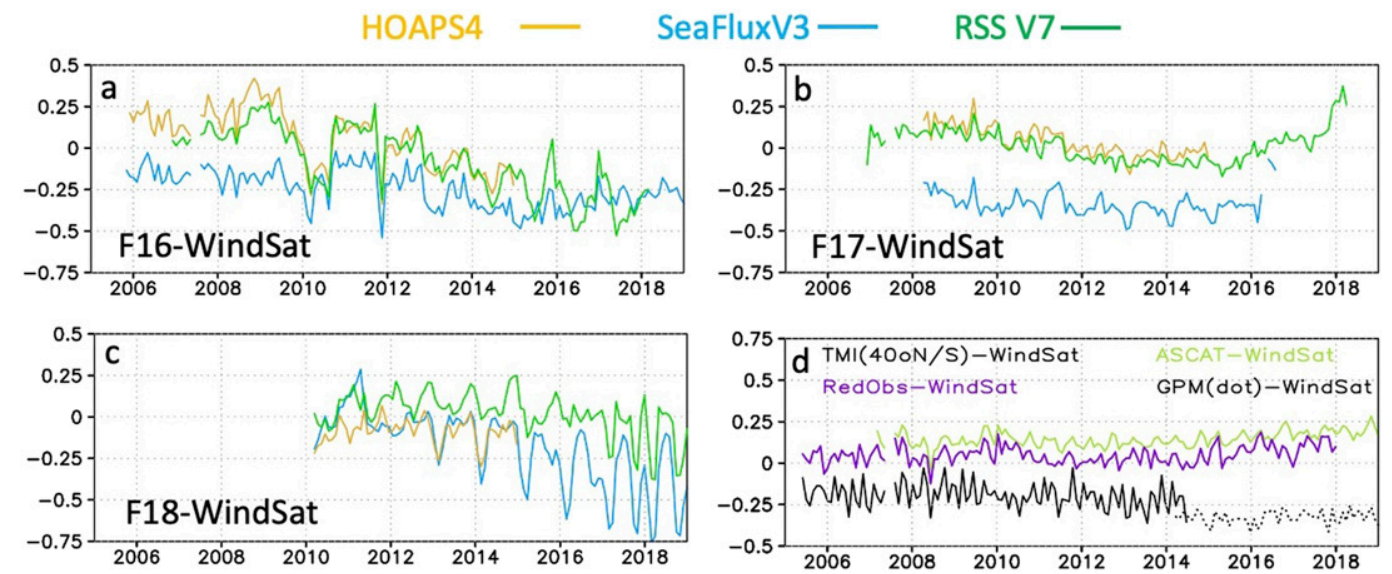

FIG. 5. Globally averaged $\left(60^{\circ} \mathrm{N} / \mathrm{S}\right)$ SSMIS (a) $F 16$, (b) $F 17$, and (c) $F 18$ minus WindSat $10-\mathrm{m}$ wind speeds (m s${ }^{-1}$ ) for three different retrieval algorithms. WindSat data are RSS retrievals. Differences are made with total signal, not anomalies. (d) 10-m wind speed differences of individual sensors and ensemble RedObs with WindSat. ASCAT wind speeds are RSS V7 products and TMI and GPM winds are produced by the SeaFlux v3 retrieval algorithm (Roberts et al. 2020). A 3-month running smoother has been applied to each time series.

behavior of ERA5 is also explored. A less-studied issue is impact of variation in $Q_{s}(\mathrm{SST})$ stemming from employing different SST analyses. SST estimates come from a research community using algorithms that do not simultaneously retrieve other geophysical quantities. So physical consistency between $Q_{a}$ retrievals and $Q_{s}(\mathrm{SST})$ is not guaranteed. This is exactly so for HOAPS4 and JOFURO3 since their specified SST fields, though different from each other, do not enter directly into the $Q_{a}$ algorithm. SeaFluxV3 uses the OISST-A with a specified diurnal cycle applied as input and is very weakly impacted by the NN retrieval. IFREMER4, however,
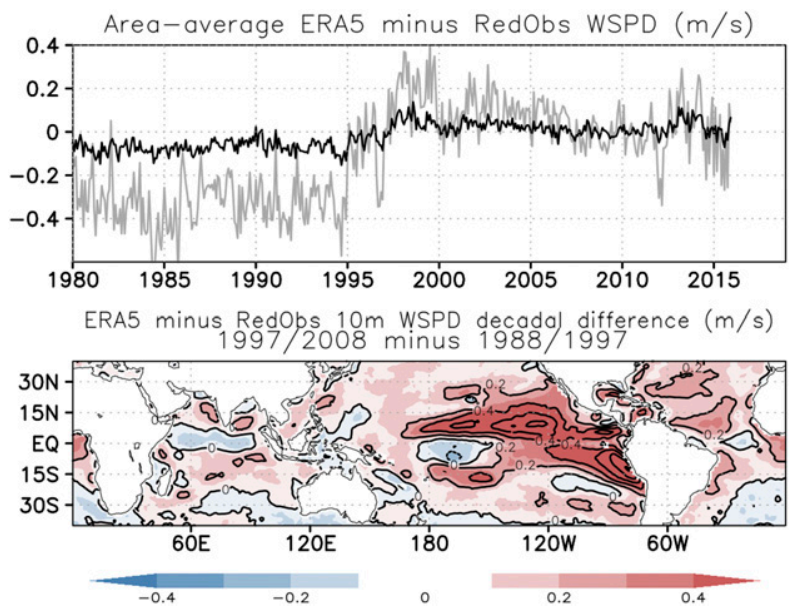

FIG. 6. (a) Time series of area-averaged ERA5 minus RedObs 10 - $\mathrm{m}$ wind speed $\left(\mathrm{m} \mathrm{s}^{-1}\right)$ over the global oceans (black) and eastern tropical Pacific $\left(180^{\circ}-290^{\circ} \mathrm{E}, 20^{\circ} \mathrm{N} / \mathrm{S}\right)$ domain (gray). (b) Decadal difference (1997-2008 minus 1988-97) of ERA5 minus RedObs 10-m wind speed $\left(\mathrm{m} \mathrm{s}^{-1}\right)$. does incorporate ERA-I SST in its $Q_{a}$ retrieval. We use CCI Level 4 SST to benchmark these differences and also compare with ERSST-5 and COBE-2 data.

1) $Q_{a}$

ENSO variability dominates global mean $Q_{a}$ signals (Figs. 7a,b). This is partly because of the nonlinear Clausius-Clapeyron (C-C) temperature/moisture relationship amplifying tropical signals over those in higher latitudes. But given the lagged remote SST response to SST forcing in the central and eastern equatorial Pacific (Klein et al. 1999; Alexander et al. 2002) the signal is not purely from the eastern Pacific. There is good agreement between all $Q_{a}$ values at the interannual scale. Note, however, the post-June 2017 drop in IFREMER4 $Q_{a}$ induced by the FCDR change. At decadal scales there is an upward trend in $Q_{a}$ with subtle yet important differences in the datasets (Table 4, Fig. 7c). Over the 1990-2010 period ERA5 has the lowest and CERA20C the largest trend $\left(2.3 \%\right.$ and $9.6 \% \mathrm{~K}^{-1}$, respectively). The retrievals tend to be somewhat below, and the RedObs above, a C-C rate of $\sim 6.5 \% \mathrm{~K}^{-1}$. These trends are somewhat sensitive to the period chosen. Using the 1993-2010 period increases the rates on the order of $15 \%$ and perhaps double that for ERA5 (from 2.3\% to $3.0 \% \mathrm{~K}^{-1}$ ). But the RedObs remain larger and ERA5 much lower compared to the satellite retrievals.

Differencing the satellite and ERA5 $Q_{a}$ from RedObs values (Fig. 7c) provides a closer look at temporal consistency. Although assimilating model physics, SST choice, and assimilated conventional observations determine the RedObs $Q_{s}-Q_{a}$ variability, the omission of assimilated satellite moisture data enables an internally 

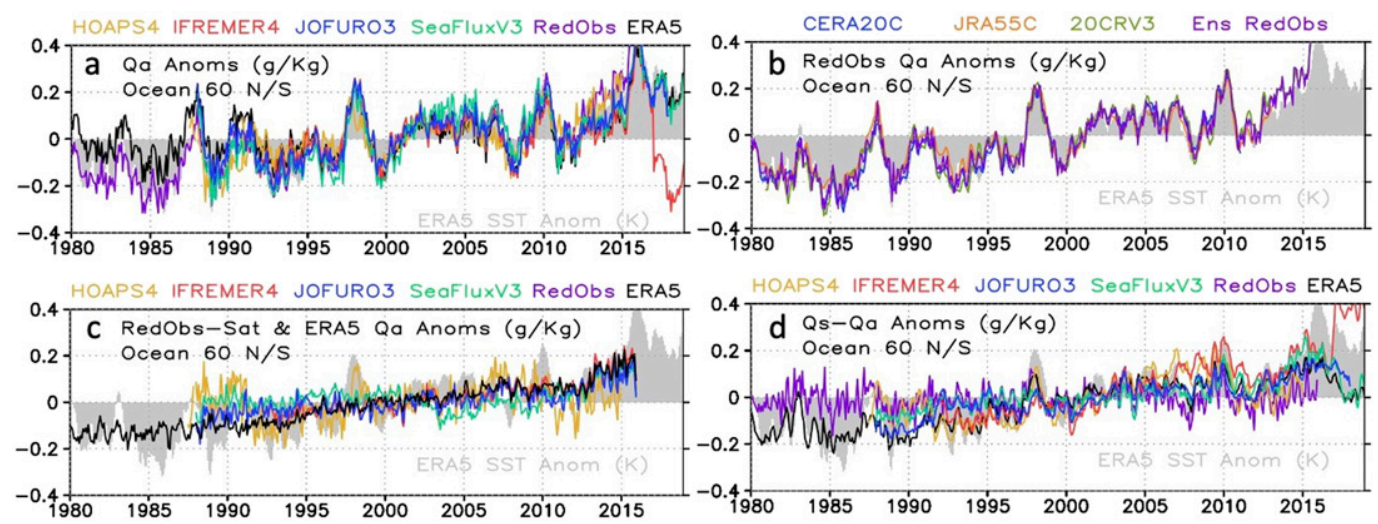

FIG. 7. Global ocean area averaged $\left(60^{\circ} \mathrm{N} / \mathrm{S}\right)$ time series $\left(\mathrm{g} \mathrm{kg}^{-1}\right)$ of (a) $Q_{a}$ anomalies of retrievals and reanalyses, (b) $Q_{a}$ anomalies of individual RedObs and their ensemble mean, (c) anomaly differences of $Q_{a}$ relative to RedObs, and (d) anomalies of $Q_{s}-Q_{a}$ for retrievals, RedObs, and ERA5. Gray shading is ERA5 SST anomalies $(K)$. A 3-month running mean smoother has been applied.

consistent, if qualitative, benchmark. ERA5 is biased moist compared to the RedObs before the mid-1990s and then becomes drier than the RedObs. This difference trend arises almost entirely over the deep tropics (not shown). We hypothesize that the gradual increase in assimilated satellite data permits stronger drying to combat a climatological model moist bias when run in a free, nonassimilating mode. Further analysis of ERA5 analysis increments is needed to evaluate this. Overall, HOAPS4 has no trend relative the RedObs but it has offsets relative to RedObs (mainly the sudden drop in 1991). SeaFluxV3 drops from slightly positive to negative differences relative to the RedObs after 2003 but becomes larger after 2010. All of the datasets show a strong $Q_{a}$ increase after 2012, but during this period only one RedObs (20CRv3) is available so the origin of this disagreement is not yet clear.

2) $Q_{s}-Q_{a}$

Global mean $Q_{s}-Q_{a}$ variations (Fig. 7d) have smaller amplitude than $Q_{a}$ due to the strong thermodynamic coupling of the overlying air to the ocean surface. Global time series still indicate positive excursions associated with the large 1997, 2010, and 2015 El Niño events. Distinct upward trends are noted for the satellite retrievals (and the ERA5 reanalysis if the pre-1988 period is considered). For the $1992-2010$ period the IFREMER 4 rate of increase of $36.6 \% \mathrm{~K}^{-1}$ (using ERA5 SSTs) is nearly matched by HOAPS $4\left(30.0 \% \mathrm{~K}^{-1}\right)$, the former driven in part by large positive $Q_{s}$ excursions in the 2007-11 period associated with a positive jump in the OISST-A SST version used by IFREMER4 (discussed below). In contrast, the RedObs have almost no significant trend $\left(1.7 \% \mathrm{~K}^{-1}\right)$. IFREMER4 also shows a jump in July 2017 coincident with change from the CSU to RSS FCDR mirroring the downward step in $Q_{a}$ (Fig. 7a). ERA5 $Q_{s}-Q_{a}$ anomalies are persistently negative prior to SSM/I ingest in 1988 but increase to positive values after the mid-1990s as the SSM/I sensor population becomes more robust. We examine the effects of SST uncertainty more closely below.

\section{3) $Q_{s}$}

Recall that three of the LHF algorithms (IFREMER4, HOAPS4, and SeaFluxV3) use OISST-A, while JOFURO3 employs its own ensemble median SST record, EMSST (Tomita et al. 2018). COBE and HADISST 2.2 SSTs are used in the RedObs. In examining the SST records used by the satellite estimates and the reanalyses, we found a larger global mean trend associated with OISST-A is present relative to that of RedObs, ERSST-5, ERA5, JOFURO3, and CCI v2.1 (not shown), but with significant interdecadal variability in difference values. Banzon et al. (2016) and Fiedler et al. (2019) note that AVHRR input to OISST-A changed from the NOAA Pathfinder to the U.S. Navy Operational product in 2007. A change from ICOADS 2.4 to NCEP SST calibration data also occurred. Figure 8 shows differences

TABLE 4. Global mean $\left(60^{\circ} \mathrm{N} / \mathrm{S}\right)$ trends of various $Q_{a}$ retrievals, RedObs members, and ERA5 over the period January 1990-December 2010. Units are percent per kelvin SST change; 1.0 SD trend errors are in parentheses.

\begin{tabular}{lcccccccc}
\hline \hline & IFREMER4 & JOFURO3 & SeaFluxV3 & HOAPS4 & CERA20C & JRA55C & 20CRv3 & ERA5 \\
\hline Trend $\left(\% \mathrm{~K}^{-1} \delta S S T\right)$ & $4.9(1.9)$ & $4.8(2.3)$ & $8.3(2.7)$ & $3.2(1.9)$ & $9.6(2.5)$ & $6.0(2.4)$ & $8.8(2.5)$ & $2.3(2.0)$ \\
\hline
\end{tabular}




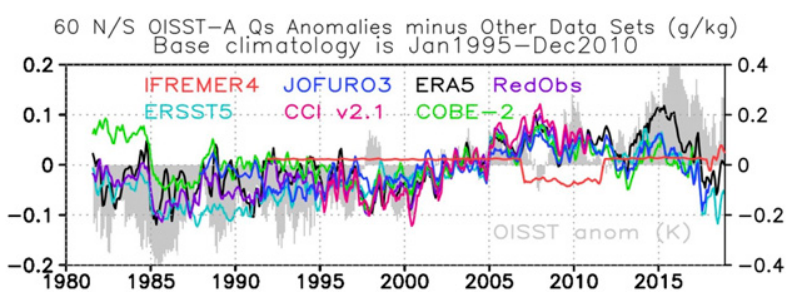

FIG. 8. Differences in $Q_{s}$ anomalies (OISST AVHRR-Only minus various datasets) averaged over $60^{\circ} \mathrm{N} / \mathrm{S}$ global domain $\left(\mathrm{g} \mathrm{kg}^{-1}\right.$; left axis). Anomalies are with respect to a 1995-2010 base climatology. OISST-A SST anomalies are shaded ( $K$; right axis). A 3-month running mean smoother has been applied.

between anomalies of $Q_{s}$ (SST) based on OISST-A and those of other datasets. (Note that here anomalies are based on a 1995-2010 climatology spanning the ATSR SSTs). HOAPS4 and SeaFluxV3, which use only OISST-A, are not shown since their differences are much smaller. IFREMER4 also uses OISST-A; however, it uses a different version during the period January 2007 through December 2011 since there is a temporary $Q_{s}$ increase of $\sim 0.05 \mathrm{~g} \mathrm{~kg}^{-1}$ globally averaged. CCI v2.1 is thought to have a stability relative to drifting buoys of $0.003 \mathrm{~K} \mathrm{yr}^{-1}$ at the $95 \%$ confidence level (Merchant et al. 2019). For a representative $Q_{s}(\mathrm{SST})$ of $20 \mathrm{~g} \mathrm{~kg}^{-1}$ and an assumed Clausius-Clapeyron rate of $Q_{s}$ change this corresponds to about $1.5 \mathrm{~g} \mathrm{~kg}^{-1} \mathrm{~K}^{-1}$. So, for an SST trend precision of $0.03 \mathrm{~K} \mathrm{decade}^{-1}$ this amounts to a $Q_{s}$ trend uncertainty of $\sim 0.05 \mathrm{~g} \mathrm{~kg}^{-1}$ decade $^{-1}$. Between the late 1990s and late 2000s, OISST-A develops the largest $Q_{s}$ exceedance over other datasets before then relaxing to little difference by 2012 . For the period 1997-2009 (picked to start and end in the years of developing ENSO warm events to minimize any bias) the difference in $Q_{s}$ trends for OISST-A minus CCI v2.1 is $0.14 \mathrm{~g} \mathrm{~kg}^{-1} \mathrm{decade}^{-1}$, a value roughly 3 times as large as the CCI v2.1 trend uncertainty. Other SST datasets aside from OISST-A show upward $Q_{s}$ difference trends that are smaller but exceed the CCI v2.1 $Q_{s}$ uncertainty (Table 5). In short, OISST-A is used in several of the satellite-based LHF records, but its trend appears as an outlier among several independently constructed SST estimates.

The spatial structure of these $Q_{s}$ trend differences with CCI v2.1 is concentrated in the tropical band, $30^{\circ} \mathrm{N} / \mathrm{S}$, and primarily over the Pacific (Fig. 9). The maxima tend to be focused off the equator at roughly $15^{\circ}-20^{\circ} \mathrm{N} / \mathrm{S}$ with peak differences near $0.4 \mathrm{~g} \mathrm{~kg}^{-1}$. Some negative areas indicating OISST-A $Q_{s}$ trends weakening compared to the others also are present, primarily over the extratropical North Pacific. Very similar $Q_{s}$ trend difference patterns and amplitudes are present for the RedObs (Fig. 9b). JOFURO3 differences reveal a similar pattern but with reduced amplitudes (not shown).

Taken together these diagnostics of SST and $Q_{s}$ raise concerns about the impact of SST choices used in LHF estimates as well as uncertainties present in each of the datasets discussed. Comparing Figs. 7d and 8, it is apparent that global mean $Q s$ trend uncertainties on the order of $0.05-0.10 \mathrm{~g} \mathrm{~kg}^{-1}$ decade $^{-1}$ are significant compared to $Q_{s}-Q_{a}$ variability. In fact, the inference from Fig. 8 is that if CCI v2.1 were used for the satellite LHF estimates, the $Q_{s}-Q_{a}$ trends would be substantially reduced and closer to that of the RedObs.

\section{Spatial structure of decadal-scale trends}

The focus of our analysis has been on assessing the diversity of algorithm differences, sensor intercalibration uncertainties, and bulk aerodynamic meteorological forcing dataset characteristics. We now examine how these factors contribute to thermodynamic and kinematic processes that generate variability at the longest scale that the near-30-yr satellite record can support.

By logarithmically differentiating the LHF formula [Eq. (1)] with respect to time, we can write

$$
\frac{d \mathrm{LHF}}{d t}=\frac{\widehat{\mathrm{LHF}}}{\hat{U}} \frac{d U}{d t}+\frac{\widehat{\mathrm{LHF}}}{Q_{s-Q_{a}}} \frac{d}{d t}\left(Q_{s}-Q_{a}\right),
$$

where we now assume $\rho_{o}, C_{E}$, and $L_{V}$ are invariant. This formulation allows us to estimate separate contributions by winds $U$ and thermodynamics to LHF changes. We evaluate the temporal change terms by differencing decadal means of the quantities and using the climatological quantities denoted by the "hat" operator. Resulting maps of LHF trends and the two contributing factors (Fig. 10) indicate significant agreement in largescale structure between the satellite estimates and the RedObs reanalyses. Particularly for wind speed,

TABLE 5. The $Q_{s}$ difference trends (OISST minus others; $\mathrm{g} \mathrm{kg}^{-1} \mathrm{decade}^{-1}$ ) over the period January 1997 through December 2009. Values are for averages over the global oceans, $60^{\circ} \mathrm{N} / \mathrm{S}$.

\begin{tabular}{|c|c|c|c|c|c|c|c|c|}
\hline & $\begin{array}{l}\text { CCI } \\
\mathrm{v} 2.1\end{array}$ & $\begin{array}{l}\text { Ensemble } \\
\text { RedObs }\end{array}$ & ERSST5 & COBE2 & JOFURO3 & HOAPS4 & IFREMER4 & SeaFluxV3 \\
\hline $\begin{array}{l}Q_{s} \text { OISST minus }(\ldots) \\
\quad\left(\mathrm{g} \mathrm{kg}^{-1} \text { decade }^{-1}\right)\end{array}$ & 0.12 & 0.11 & 0.09 & 0.08 & 0.07 & 0.0 & -0.03 & 0.01 \\
\hline
\end{tabular}




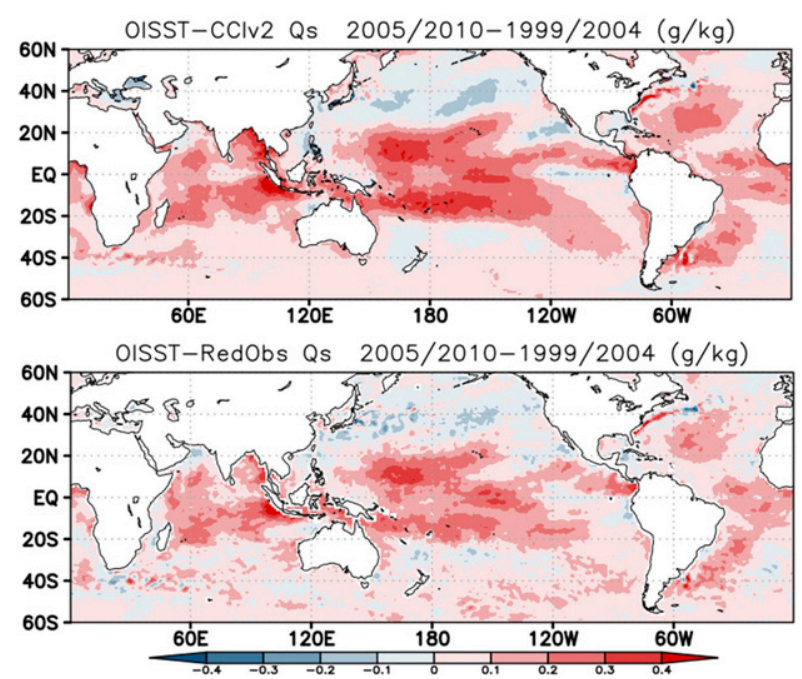

FIG. 9. The $Q_{s}$ differences ( $\mathrm{g} \mathrm{kg}^{-1}$ ) between $2005-10$ and 1999 2004 periods for (a) OISST minus CCIv2 and (b) OISST minus ensemble mean RedObs.

prominent central equatorial Pacific increases are producing LHF increases of order $10-15 \mathrm{~W} \mathrm{~m}^{-2}$. This ramp up in tropical central and eastern Pacific wind speed is associated with the so-called warming hiatus (Kosaka and Xie 2013; de Boisséson et al. 2014; England et al. 2014) characterized by increased SST and surface pressure contrast across the equatorial Pacific. Immediately to the southwest, wind-driven LHF decreases are common to all estimates and the reanalyses. Offsetting these wind speed effects is a wedge-shaped area of $Q_{s}-Q_{a}$ driven LHF decreases just to the east and fanning out poleward along the western coasts of the Americas. These changes are also consistent with the "warming hiatus" and the change in sign of the IPO occurring sometime near 2000 (Henley et al. 2015), which was characterized by a switch toward cooler SSTs in this wedge-shaped area east of the date line. The RedObs trends replicate this structure of LHF changes, even with some regional fidelity, including the westward extension of LHF decreases off the coasts of Peru and western North America and the centroid of LHF increases over the area near $160^{\circ} \mathrm{W}, 7.5^{\circ} \mathrm{S}$, with negative values immediately to the southwest. The RedObs and SeaFluxV3 show closest agreement in the $Q_{s}-Q_{a}$-driven LHF decreases. There are notable structural differences between the ERA5 LHF trends and those of both RedObs and the satellite estimates stemming in particular from the large lobe of high wind speed trends in the North Pacific discussed with Fig. 6b. The decadal-scale $Q_{s}-Q_{a}$ decreases in that region are also weaker than in the other datasets.

Especially notable in JOFURO3 and IFREMER4 are "bull's eye" LHF structures located in the TAO buoy array along the equatorial Pacific that relate to $Q_{s}-Q_{a}$ changes. We noted in section 2 that both of these algorithms use other information in addition to the channel brightness temperatures to account for varying dependence of $Q_{a}$ with vertical moisture and temperature stratification. JOFURO3 used ERA-I moisture profile data in identifying six scale height bins that were used to develop $Q_{a}$ retrievals. In the case of IFREMER4, ERAI SST $-T_{2 \mathrm{~m}}$ stability data were used as a $Q_{a}$ predictor and ERA-I $Q_{a}$ data were used to fill daily data voids globally via a temporal drift constraint. Indeed, we find over the 1992-2014 period the correlation between ERA-I and IFREMER $4 Q_{a}$ averaged over the $60^{\circ} \mathrm{N} / \mathrm{S}$ domain is 0.98. Josey et al. (2014) noted that time-dependent $Q_{a}$ biases in the ERA-I analysis over the equatorial Pacific, relative to buoy values, exhibited these bull's eye patterns. Thus, it is likely that the assimilation of buoy data is acting to correct regime-dependent biases in the ERA-I assimilating model. These time-dependent moisture biases in ERA-I are apparently being transferred to some degree to the JOFURO3 and IFREMER4 $Q_{a}$ retrievals. These artifacts are not apparent in the RedObs, HOAPS4, or SeaFluxV3. The latter uses relative vertical moisture structure from MERRA-2. Overall, the satellite estimates exhibit a larger $Q_{s}-Q_{a}$ contribution to upward LHF trends compared to the RedObs. This is related to the larger upward trend of $Q_{s}(\mathrm{SST})$ used in the satellite estimates (Fig. 8) as well as their weaker upward $Q_{a}$ trends (Fig. 7).

\section{Discussion and final remarks}

We have analyzed four recently updated state-of-theart satellite LHF estimates, focusing on variability of near-global, over-ocean averages as well as regional trends and pattern agreement. A number of other datasets have served as critical comparison points. Among these are three reduced observation reanalyses, a budget residual LHF estimate combining GPCP and RSS satellite precipitation and reanalysis assimilated $\operatorname{Div}(q V)$; ERA5, the most recent comprehensive reanalysis; RSS singlesensor passive microwave and scatterometer wind speed retrievals; and a selection of SST datasets including CCI v2.1.

A central question of our analysis was the degree to which consistency in interannual to decadal LHF variability could be found among these datasets. We showed that, at the global scale, satellite LHF trends during the 1990-2010 period are 3-5 times larger than those of the RedObs and residually diagnosed estimates (Figs. 1 and 2). These latter two sources together provide evidence that existing upward trends in global ocean satellite LHF products are exaggerated to varying degrees. We 

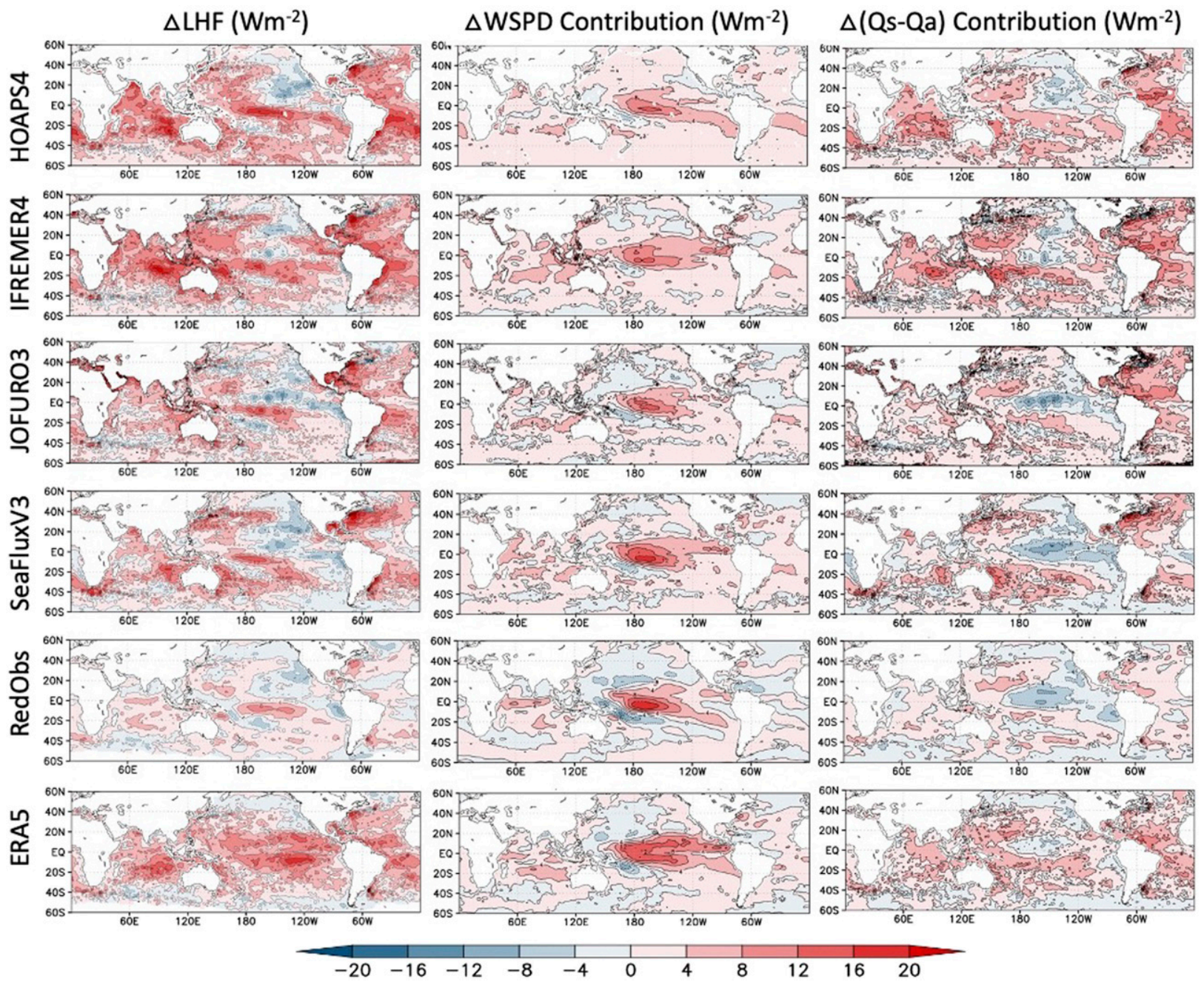

FIG. 10. (left) LHF decadal differences ( $\mathrm{W} \mathrm{m}^{-2}$ ), 2010-1999 minus 1999-90, for satellite retrievals (IFREMER4, HOAPS4, JOFURO3, SeaFluxV3), RedObs ensemble (CERA20C, JRA55C, 20CRv3), and ERA5. (center) 10-m WSPD contribution to the LHF decadal difference $\left(\mathrm{W} \mathrm{m}^{-2}\right.$ ). (right) $Q_{s}-Q_{a}$ contribution to the LHF decadal difference ( $\mathrm{W} \mathrm{m}^{-2}$ ). See text for explanation of how contributions are calculated.

emphasize that the interdecadal trend studied here is not to be construed as a secular trend but rather as a sampling-dependent estimate of internal climate variability for the current satellite record. In terms of regional trend structure over the 1990-2010 period, there is significant commonality in the patterns among the satellite estimates and the RedObs ensemble (Fig. 10), most notably in the strong wind speed increases in the central Pacific associated with the increasingly negative IPO index (de Boisséson et al. 2014; England et al. 2014) and the "warming hiatus" (Easterling and Wehner 2009). The $Q_{s}-Q_{a}$ trend patterns show somewhat lesser regional similarity among the estimates and the ensemble RedObs reanalyses with satellite estimates showing consistently larger positive trend pattern amplitudes than the RedObs.
Another leading objective of this work was to trace differences in LHF variability to various algorithm approaches in satellite-derived meteorological forcing (wind speed, near-surface humidity) and associated differences in FCDR Tbs. Our analysis has identified what we believe to be systematic discrepancies:

1) SSMIS wind speeds $(F 16, F 17$, and $F 18)$ exhibit ephemeral or episodic differences compared with other more stable sensors: WindSat, ASCAT, and TMI. F16 and F18 are more problematic than F17 and also happen to have orbits that drift substantially through the diurnal cycle. Given the more serious problems of solar reflector intrusions into the warm load reference targets and unknown emissivities of the reflector (e.g., Kunkee et al. 2008) compared to 
that of their SSM/I counterparts it may be that these factors interact in some way that has yet to be fully resolved by any of the FCDRs. The difficulties apparently affect the $37-\mathrm{GHz}$ channel the most since $Q_{a}$ retrieval disparities are not nearly as noticeable.

2) Figure 7 a provides evidence for strong agreement in global $Q_{a}$ retrieval response to ENSO interannual variability. At the same time, Fig. 7c illustrates that there are time-dependent offsets relative to the RedObs for some $Q_{a}$ retrievals. Whether these differences arise from weather regime dependencies in the retrievals or remaining sensor intercalibration issues remains to be understood. As demonstrated by Bentamy et al. (2013), Tomita et al. (2018), and Roberts et al. (2019), regime dependencies in $Q_{a}$ that are associated with synoptic weather states can be handled by appealing to ancillary data, yielding measurable improvements in $Q_{a}$ estimates. However, current ancillary data are not independent of reanalysis vagaries. For example, the biases in ERA-I $Q_{a}$ related to the assimilation of TAO buoy moisture (Josey et al. 2014) produce spatial noise in trend patterns over the 1990-2010 period for both IFREMER4 and JOFURO3 (Fig. 10). SeaFluxV3 apparently avoids this problem by use of MERRA-2 as ancillary data. It would be preferable if, in the future, estimating water vapor scale height could be done independently of reanalysis fields. For example, TOA shortwave and longwave radiative fluxes, cloud forcing, and SST might be used to identify synoptic regimes via their tie to atmospheric dynamics.

3) Historically, there has been little attention paid to the degree to which $Q_{s}(\mathrm{SST})$ from different SST datasets affects LHF estimates. Our analysis shows that in terms of decadal length trends, there exist important differences between OISST-A data used in three of the new estimates (HOAPS4, SeaFluxV3, and IFREMER4) and other current global SST datasets when compared to the CCI v2.1 standard. The change from NOAA Pathfinder to U.S. Navy operational AVHRR data as well as changes in ICOADS calibrating data are likely sources producing this elevated SST trend. Our analysis suggests that OISST-A-based $Q_{s}$ trends may be too large over the 1997-2010 period, possibly in the range of $0.05-0.10 \mathrm{~g} \mathrm{~kg}^{-1} \mathrm{decade}^{-1}$, globally averaged. A number of other datasets show similar differences during this period. A more immediately addressable problem exists in IFREMER4 where for the period 2007-11 a different version of OISST-A has been used.

Our analysis also identifies other concerns. To extend IFREMER 4.0 to 4.1, a switch from the CSU to the RSS
FCDR has resulted in an inadvertent decrease in retrieved $Q_{a}$ (Figs. 7a,d). Absolute differences in brightness temperatures between FCDRs on the order of $1 \mathrm{~K}$ can arise because of different radiative transfer codes involved in the intercalibration process. Since IFREMER4.1 uses scatterometer and RSS retrieved winds the sudden increase in LHF (Fig. 1a) occurs solely through the $Q_{a}$ discontinuity. Of more fundamental importance is the sparse data coverage early in the SSM/ I era. The single satellite coverage of F08 (late 1987-91) and its 1-yr overlap with $F 10$, which has an anomalously eccentric orbit and precession of equator crossing time, serve to increase uncertainties across datasets early in the record. Wentz (2013) document suspiciously low antenna temperatures in the first two years of F11 but these apparent problems are not evident in the CM SAF, CSU, or GPM intercalibrated brightness temperatures.

We have also detected a significant upward trend in ERA5 LHF compared to RedObs, which assimilate no passive microwave data. A small but detectable jump in ERA5 wind speed during the mid-1990s is present in conjunction with the addition of the ERS-1 and ERS-2 scatterometer data streams and the increase in SSM/I coverage. Furthermore, ERA5 $Q_{a}$ anomalies are more moist than RedObs values before the mid-1990s but do not trend upward in time as much as the RedObs; thus, ERA5 $Q_{s}-Q_{a}$ increases aid in the upward LHF trend. Although RedObs climate model physics may possibly constrain a more muted moisture variability we believe the results more likely underscore the persistent problem of the heterogeneous and discrete nature of the satellite record (here, passive microwave moisture) resulting in a time-dependent ability to adjust assimilation model climatological biases.

The three RedObs reanalyses combined with an independent residual-based LHF estimate are essential components of our analysis. While they cannot be regarded as absolute validation, the consistency between these two estimates has enabled us to narrow the uncertainties for global trends during the satellite era. This result justified using the RedObs to detect suspicious wind trends and anomalies in SSMIS wind retrievals (Fig. 5), identify possible intercalibration problems in $Q_{a}$ retrievals (Fig. 7c), and suggested the presence of spurious changes in ERA5 $Q_{a}$ and 10-m wind speed (Figs. 6, 7). While likely not adept in capturing the details of synoptic-scale wind speed variability in the tropics (Compo et al. 2006), the RedObs do capture interannual to decadal scale changes. Regional details and the overall agreement of trend patterns in LHF, wind speed, and $Q_{a}$ between the RedObs and the satellite estimates in Fig. 10 are a strong partial validation. 
Three recommendations also emerge from our analysis. We urge that the turbulent flux retrieval community place more emphasis on intercomparing FCDRs, perhaps facilitated by a workshop to foster collaboration on sensor intercalibration. SSMIS issues in particular should be targeted. Also, of high importance is a more thorough assessment of SST datasets in the context of $Q_{s}-Q_{a}$ "regimes," better estimates of skin temperature including the effects of diurnal variability, and multidecadal trends. Finally, we urge operational centers to prioritize the production of RedObs experiments to accompany all reanalyses, to extend them back as many decades as is feasible, and to keep them updated to real time. This will help bridge satellite flux estimates, reanalyses, and climate simulations in working toward narrowing uncertainties in answering the question "How is the water cycle changing?".

Acknowledgments. FRR, JBR, and MGB acknowledge support for this investigation through the NASA Energy and Water Cycle Study (NEWS), Dr. Jared Entin, Program Manager. MS acknowledges the financial support by the EUMETSAT member states through CM SAF. The NOAA-CIRES-DOE Twentieth Century Reanalysis Project version 3 used resources of the National Energy Research Scientific Computing Center managed by Lawrence Berkeley National Laboratory, which is supported by the Office of Science of the U.S. Department of Energy under Contract DE-AC0205CH11231 and used resources of NOAA's remotely deployed high-performance computing systems. Support for the Twentieth Century Reanalysis Project version 3 dataset is provided by the U.S. DOE, Office of Science Biological and Environmental Research (BER), by the NOAA Climate Program Office, and by the NOAA Physical Sciences Laboratory. RSS products are supported by funding from the NASA Earth Science Division. H. Tomita acknowledges support from JSPS Grants JP18H03726, JP18H03737, and JP19H05696 and JAXA Announcement EO-2. We gratefully acknowledge provision and institutional support for the following SST datasets: ESA CCI (http://data.ceda.ac.uk/ neodc/esacci/sst/data/CDR_v2/); NOAA Optimum Interpolation 1/4 Degree Daily Sea Surface Temperature (OISST) Analysis, version 2, (https:/doi.org/10.7289/ V5SQ8XB5); NOAA ERSST v5 (https:/doi.org/10.7289/ V5T72FNM) and access to COBE-SST2 provided by the NOAA/OAR/ESRL PSD (boyin.huang@noaa.gov); 20CRv3 data are available at the NERSC Science Tape Gateway via portal.nersc.gov. The authors also thank two anonymous reviewers whose comments improved an earlier version of this paper.

\section{REFERENCES}

Adler, R. F., G. Gu, M. Sapiano, J. Wang, and G. J. Huffman, 2017: Global precipitation: Means, variations and trends during the satellite era (1979-2014). Surv. Geophys., 38, 679-699, https:// doi.org/10.1007/s10712-017-9416-4.

— , and Coauthors, 2018: The Global Precipitation Climatology Project (GPCP) monthly analysis (new version 2.3) and a review of 2017 global precipitation. Atmosphere, 9, 138, https:// doi.org/10.3390/atmos9040138.

Alexander, M. A., I. Bladé, M. Newman, J. R. Lanzante, N.-C. Lau, and J. D. Scott, 2002: The atmospheric bridge: The influence of ENSO teleconnections on air-sea interaction over the global oceans. J. Climate, 15, 2205-2231, https://doi.org/10.1175/15200442(2002)015<2205:TABTIO > 2.0.CO;2.

Allan, R. P., C. Liu, M. D. Zahn, A. Lavers, E. Koukouvagias, and A. Bodas-Salcedo, 2013: Physically consistent responses of the global atmospheric hydrological cycle in models and observations. Surv. Geophys., 35, 533-552, https://doi.org/10.1007/ s10712-012-9213-z.

Allen, M. R., and W. J. Ingram, 2002: Constraints on future changes in climate and the hydrologic cycle. Nature, 419, 228-232, https://doi.org/10.1038/nature01092.

Andersson, A., K. Fennig, C. Klepp, S. Bakan, H. Graß1, and J. Schulz, 2010: The Hamburg Ocean atmosphere parameters and fluxes from satellite data-HOAPS-3. Earth Syst. Sci. Data, 2, 215-234, https://doi.org/10.5194/essd-2-215-2010.

Banzon, V., T. M. Smith, T. M. Chin, C. Y. Liu, and W. Hankins, 2016: A long-term record of blended satellite and in situ seasurface temperature for climate monitoring, modeling and environmental studies. Earth Syst. Sci. Data, 8, 165-176, https://doi.org/10.5194/essd-8-165-2016.

Bell, W., and Coauthors, 2008: The assimilation of SSMIS radiances in numerical weather prediction models. IEEE Trans. Geosci. Remote Sens., 46, 884-900, https://doi.org/10.1109/ TGRS.2008.917335.

Bentamy, A., K. Katsaros, A. Mestas-Nuñez, W. Drennan, E. Ford, and H. Roquet, 2003: Satellite estimates of wind speed and latent heat flux over the global oceans. J. Climate, 16, 637-656, https:// doi.org/10.1175/1520-0442(2003)016<0637:SEOWSA $>2.0 . C O ; 2$. , S. A. Grodsky, J. A. Carton, D. Croizé-Fillon, and B. Chapron, 2012: Matching ASCAT and QuikSCAT winds. J. Geophys. Res., 117, C02011, https://doi.org/10.1029/2011JC007479.

, - - K. Katsaros, A. M. Mestas-Nuñez, B. Blanke, and F. Desbiolles, 2013: Improvement in air-sea flux estimates derived from satellite observations. Int. J. Remote Sens., 34, 5243-5261, https://doi.org/10.1080/01431161.2013.787502.

, - E. Anis, C. Bertrand, and F. Desbiolles, 2017: Homogenization of scatterometer wind retrievals. Int. J. Climatol., 37, 870-889, https://doi.org/10.1002/joc.4746.

Berg, W., and M. R. P. Sapiano, 2013: Corrections and APC for SSMIS Ta to Tb. CSU Tech. Rep., Colorado State University, 31 pp., http://rain.atmos.colostate.edu/FCDR/doc/CSU_FCDR_ ssmis_corrections_tech_report.pdf.

— , R. Kroodsma, C. D. Kummerow, and D. S. McKague, 2018: Fundamental climate data records of microwave brightness temperatures. Remote Sens., 10, 1306, https://doi.org/10.3390/rs10081306.

Berry, D. I., and E. C. Kent, 2017: Assessing the health of the in situ global surface marine climate observing system. Int. J. Climatol., 37, 2248-2259, https://doi.org/10.1002/joc.4914.

Bjerknes, J., 1969: Atmospheric teleconnections from the equatorial Pacific. Mon. Wea. Rev., 97, 163-172, https://doi.org/ 10.1175/1520-0493(1969)097<0163:ATFTEP >2.3.CO;2. 
Bloom, S., L. Takacs, A. DaSilva, and D. Ledvina, 1996: Data assimilation using incremental analysis updates. Mon. Wea. Rev., 124, 1256-1271, https://doi.org/10.1175/1520-0493(1996) 124<1256:DAUIAU $>2.0$.CO;2.

Boening, C., J. K. Willis, F. W. Landerer, R. S. Nerem, and J. Fasullo, 2012: The 2011 La Niña: So strong, the oceans fell. Geophys. Res. Lett., 39, L19602, https://doi.org/10.1029/ $2012 \mathrm{gl} 053055$.

Bosilovich, M. G., F. R. Robertson, L. Takacs, A. Molod, and D. Mocko, 2017: Atmospheric water balance and variability in the MERRA-2 reanalysis. J. Climate, 30, 1177-1196, https:// doi.org/10.1175/JCLI-D-16-0338.1.

Brown, P. J., and C. D. Kummerow, 2014: An assessment of atmospheric water budget components over tropical oceans. J. Climate, 27, 2054-2071, https://doi.org/10.1175/JCLI-D-1300385.1.

Cazenave, A., and Coauthors, 2012: Estimating ENSO influence on the global mean sea level, 1993-2010. Mar. Geod., 35, 82-97, https://doi.org/10.1080/01490419.2012.718209.

Chen, J. L., C. R. Wilson, B. D. Tapley, J. S. Famiglietti, and M. Rodell, 2005: Seasonal global mean sea level change from satellite altimeter, GRACE, and geophysical models. J. Geod., 79, 532-539, https://doi.org/10.1007/s00190-005-0005-9.

Cheng, L., K. E. Trenberth, J. Fasullo, T. Boyer, J. Abraham, and J. Zhu, 2017: Improved estimates of ocean heat content from 1960 to 2015. Sci. Adv., 3, e1601545, https://doi.org/10.1126/ sciadv.1601545.

Chevallier, F., S. Di Michele and A. P. McNally, 2006: Diverse profile datasets from the ECMWF 91-level short-range forecasts, version 1.0. NWP SAF Rep. NWPSAF-EC-TR-010, 14 pp.

Compo, G. P., J. S. Whitaker, and P. D. Sardeshmukh, 2006: Feasibility of a 100-year reanalysis using only surface pressure data. Bull. Amer. Meteor. Soc., 87, 175-190, https://doi.org/ 10.1175/BAMS-87-2-175.

_ , and Coauthors, 2011: The Twentieth Century Reanalysis Project. Quart. J. Roy. Meteor. Soc., 137, 1-28, https://doi.org/ 10.1002/qj.776.

Cram, T. A., and Coauthors, 2015: The International Surface Pressure Databank version 2. Geosci. Data J., 2, 31-46, https:// doi.org/10.1002/gdj3.25.

de Boisséson, E., M. A. Balmaseda, S. Abdalla, E. Kallen, and P. A. E. M. Janssen, 2014: How robust is the recent strengthening of the tropical Pacific trade winds? Geophys. Res. Lett., 41, 4398-4405, https://doi.org/10.1002/2014GL060257.

Donlon, C. J., P. J. Minnett, C. Gentemann, T. J. Nightingale, I. J. Barton, B. Ward, and M. J. Murray, 2002: Toward improved validation of satellite sea surface skin temperature measurements for climate research. J. Climate, 15, 353-369, https://doi.org/10.1175/1520-0442(2002)015<0353:TIVOSS $>2.0$. $\mathrm{CO} ; 2$.

, M. Martin, J. Stark, J. Roberts-Jones, E. Fiedler, and W. Wimmer, 2012: The Operational Sea Surface Temperature and Sea Ice Analysis (OSTIA) system. Remote Sens. Environ., 116, 140-158, https://doi.org/10.1016/j.rse.2010.10.017.

Durack, P. J., and S. E. Wijffels, 2010: Fifty-year trends in global ocean salinities and their relationship to broad-scale warming. J. Climate, 23, 4342-4362, https://doi.org/10.1175/2010JCLI3377.1.

Easterling, D. R., and M. F. Wehner, 2009: Is the climate warming or cooling? Geophys. Res. Lett., 36, L08706, https://doi.org/ 10.1029/2009GL037810.

Edson, J. B., and Coauthors, 2013: On the exchange of momentum over the open ocean. J. Phys. Oceanogr., 43, 1589-1610, https://doi.org/10.1175/JPO-D-12-0173.1.
Embury, O., C. J. Merchant, and G. K. Corlett, 2012: A reprocessing for climate of sea surface temperature from the along-track scanning radiometers: Initial validation, accounting for skin and diurnal variability effects. Remote Sens. Environ., 116, 62-78, https://doi.org/10.1016/j.rse.2011.02.028.

England, M. H., and Coauthors, 2014: Recent intensification of wind-driven circulation in the Pacific and the ongoing warming hiatus. Nat. Climate Change, 4, 222-227, https://doi.org/ 10.1038/nclimate2106.

Fairall, C. W., E. F. Bradley, D. P. Rogers, J. B. Edson, and G. S. Young, 1996: Bulk parameterization of air-sea fluxes for Tropical Ocean-Global Atmosphere Coupled OceanAtmosphere Response Experiment. J. Geophys. Res., 101, 3747-3767, https://doi.org/10.1029/95JC03205.

,-- J. E. Hare, A. A. Grachev, and J. B. Edson, 2003: Bulk parameterization of air-sea fluxes: Updates and verification for the COARE3.0 algorithm. J. Climate, 16, 571-591, https:// doi.org/10.1175/1520-0442(2003)016<0571:BPOASF >2.0.CO;2.

Feng, X., K. Haines, and E. de Boisséson, 2018: Coupling of surface air and sea surface temperatures in the CERA-20C reanalysis. Quart. J. Roy. Meteor. Soc., 144, 195-207, https://doi.org/ 10.1002/qj.3194.

Fennig, K., A. Andersson, and M. Schröder, 2015: Fundamental climate data record of SSM/I/SSMIS brightness temperatures. Satellite Application Facility on Climate Monitoring, accessed March 2017, http://dx.doi.org/10.5676/EUM_SAF_CM/FCDR_ MWI/V002.

— M. Schröder, A. Andersson, and R. Hollmann, 2020: A fundamental climate data record of SMMR, SSM/I, and SSMIS brightness temperatures. Earth Syst. Sci. Data, 12, 647681, https://doi.org/10.5194/essd-12-647-2020.

Fiedler, E. K., and Coauthors, 2019: Intercomparison of long-term sea surface temperature analyses using the GHRSST MultiProduct Ensemble (GMPE) system. Remote Sens. Environ., 222, 18-33, https://doi.org/10.1016/j.rse.2018.12.015.

Freeman, E., and Coauthors, 2017: ICOADS release 3.0: A major update to the historical marine climate record. Int. J. Climatol., 37, 2211-2237, https://doi.org/10.1002/joc.4775.

Fujiwara, M., and Coauthors, 2017: Introduction to the SPARC Reanalysis Intercomparison Project (S-RIP) and overview of the reanalysis systems. Atmos. Chem. Phys., 17, 1417-1452, https://doi.org/10.5194/acp-17-1417-2017.

Gelaro, R., and Coauthors, 2017: The Modern-Era Retrospective Analysis for Research and Applications, version 2 (MERRA-2). J. Climate, 30, 5419-5454, https://doi.org/10.1175/JCLI-D-160758.1.

Giese, B. S., H. F. Seidel, G. P. Compo, and P. D. Sardeshmukh, 2016: An ensemble of ocean reanalyses for 1815-2013 with sparse observational input. J. Geophys. Res. Oceans, 121, 6891-6910, https://doi.org/10.1002/2016JC012079.

Good, S. A., O. Embury, C. E. Bulgin, and J. Mittaz, 2019: ESA sea surface temperature climate change initiative (CCI v2.1): Level 4 analysis climate data record, version 2.1. Centre for Environmental Data Analysis, accessed July 2019, https:// doi.org/10.5285/62c0f97b1eac4e0197a674870afe1ee6.

Held, I. M., and B. J. Soden, 2006: Robust responses of the hydrological cycle to global warming. J. Climate, 19, 5686-5699, https://doi.org/10.1175/JCLI3990.1.

Helm, K. P., N. L. Bindoff, and J. A. Church, 2010: Changes in the global hydrological-cycle inferred from ocean salinity. Geophys. Res. Lett., 37, L18701, https://doi.org/10.1029/2010GL044222.

Henley, B. J., J. Gergis, D. J. Karoly, S. Power, J. Kennedy, and C. K. Folland, 2015: A tripole index for the interdecadal 
Pacific oscillation. Climate Dyn., 45, 3077-3090, https:// doi.org/10.1007/s00382-015-2525-1.

Hersbach, H., and Coauthors, 2020: The ERA5 global reanalysis. Quart. J. Roy. Meteor. Soc., https://doi.org/10.1002/qj.3803, in press.

Hilburn, K. A., and F. J. Wentz, 2008: Intercalibrated passive microwave rain products from the Unified Microwave Ocean Retrieval Algorithm (UMORA). J. Appl. Meteor. Climatol., 47, 778-794, https://doi.org/10.1175/2007JAMC1635.1.

Hirahara, S., M. Ishii, and Y. Fukuda, 2014: Centennial-scale sea surface temperature analysis and its uncertainty. J. Climate, 27, 57-75, https://doi.org/10.1175/JCLI-D-12-00837.1.

_, M. Alonso-Balmaseda, E. de Boisseson, and H. Hersbach, 2016: Sea surface temperature and sea ice concentration for ERA5. ERA Rep. Series 26, 27 pp., https://www.ecmwf.int/en/ elibrary/16555-sea-surface-temperature-and-sea-ice-concentration-era5.

Huang, B., and Coauthors, 2017: Extended Reconstructed Sea Surface Temperature version 5 (ERSSTv5), upgrades, validations, and intercomparisons. J. Climate, 30, 8179-8205, https://doi.org/10.1175/JCLI-D-16-0836.1.

Ishii, M., A. Shouji, S. Sugimoto, and T. Matsumoto, 2005: Objective analyses of sea-surface temperature and marine meteorological variables for the 20th century using ICOADS and the Kobe Collection. Int. J. Climatol., 25, 865-879, https:// doi.org/10.1002/joc.1169.

Jackson, D. L., G. A. Wick, and F. R. Robertson, 2009: Improved multisensor approach to satellite-retrieved near-surface specific humidity observations. J. Geophys. Res., 114, D16303, https://doi.org/10.1029/2008JD011341.

Jin, X., L. Yu, D. L. Jackson, and G. A. Wick, 2015: An improved near-surface specific humidity and air temperature climatology for the SSM/I satellite period. J. Atmos. Oceanic Technol., 32, 412-433, https://doi.org/10.1175/JTECH-D-14-00080.1.

Josey, S. A., L. Yu, S. Gulev, X. Jin, N. Tilinina, B. Barnier, and L. Brodeau, 2014: Unexpected impacts of the tropical Pacific array on reanalysis surface meteorology and heat fluxes. Geophys. Res. Lett., 41, 6213-6220, https://doi.org/10.1002/2014GL061302.

Kent, E. C., D. I. Berry, S. D. Woodruff, and P. K. Taylor, 2006: Voluntary observing ships: A vital observing system in decline. CLIVAR Exchanges, No. 38, International CLIVAR Project Office, Southampton, United Kingdom, 28 pp., http:// www.clivar.org/sites/default/files/documents/Exchanges38.pdf.

Klein, S. A., B. J. Soden, and N. Lau, 1999: Remote sea surface temperature variations during ENSO: Evidence for a tropical atmospheric bridge. J. Climate, 12, 917-932, https://doi.org/ 10.1175/1520-0442(1999)012<0917:RSSTVD>2.0.CO;2.

Kobayashi, C., H. Endo, Y. Ota, S. Kobayashi, H. Onoda, Y. Harada, K. Onogi, and H. Kamahori, 2014: Preliminary results of the JRA-55C, an atmospheric reanalysis assimilating conventional observations only. SOLA, 10, 78-82, https:// doi.org/10.2151/SOLA.2014-016.

_- and Coauthors, 2015: The JRA-55 reanalysis: General specifications and basic characteristics. J. Meteor. Soc. Japan Ser. II, 93, 5-48, https://doi.org/10.2151/jmsj.2015-001.

Kosaka, Y., and S. P. Xie, 2013: Recent global-warming hiatus tied to equatorial Pacific surface cooling. Nature, 501, 403-407, https://doi.org/10.1038/nature12534

Kummerow, C. D., W. K. Berg, M. R. P. Sapiano, and NOAA CDR Program, 2013: NOAA Climate Data Record (CDR) of SSM/I and SSMIS microwave brightness temperatures, CSU version 1. NOAA National Climatic Data Center, accessed July 2017, https://doi.org/10.7289/V5CC0XMJ.
Kunkee, D. B., G. A. Poe, R. Savage, and J. Peirce, 2008: Special Sensor Microwave Imager Sounder (SSMIS) radiometric calibration anomalies Part I: Identification and characterization. IEEE Trans. Geosci. Remote Sens., 46, 1017-1033, https:// doi.org/10.1109/TGRS.2008.917213.

Laloyaux, P., M. Balmaseda, D. Dee, K. Mogensen, and P. Janssen, 2016: A coupled data assimilation system for climate reanalysis. Quart. J. Roy. Meteor. Soc., 142, 65-78, https://doi.org/10.1002/qj.2629.

— , and Coauthors, 2018: CERA-20C: A coupled reanalysis of the twentieth century. J. Adv. Model. Earth Syst., 10, 11721195, https://doi.org/10.1029/2018MS001273.

Lei, L., and J. S. Whitaker, 2016: A four-dimensional incremental analysis update for the ensemble Kalman filter. Mon. Wea. Rev., 144, 2605-2621, https://doi.org/10.1175/MWR-D-15-0246.1.

Liu, C., and Coauthors, 2015: Combining satellite observations and reanalysis energy transports to estimate global net surface energy fluxes 1985-2012. J. Geophys. Res. Atmos., 120, 93749389, https://doi.org/10.1002/2015JD023264.

_ based global net surface energy flux and uncertainty estimates. J. Geophys. Res. Atmos., 122, 6250-6272, https://doi.org/ 10.1002/2017jd026616.

Liu, W. T., 1984: Estimation of latent heat flux with SeasatSMMR, a case study in N. Atlantic. Large-Scale Oceanographic Experiments and Satellites, C. Gautier and M. Fieux, Eds., NATO ASI Series (Series C: Mathematical and Physical Sciences), Vol. 128, Springer, 205-221.

, 1988: Moisture and latent heat flux variabilities in the tropical Pacific derived from satellite data. J. Geophys. Res., 93, 67496760, https://doi.org/10.1029/JC093iC06p06749.

Loeb, N., J. M. Lyman, G. C. Johnson, R. P. Allan, D. R. Doelling, T. Wong, B. J. Soden, and G. L. Stephens, 2012: Observed changes in top-of-the-atmosphere radiation and upper-ocean heating consistent within uncertainty. Nat. Geosci., 5, 110-113, https://doi.org/10.1038/ngeo1375.

Manabe, S., and R. T. Wetherald, 1975: The effects of doubling the $\mathrm{CO}_{2}$ concentration on the climate of a general circulation model. J. Atmos. Sci., 32, 3-15, https://doi.org/10.1175/15200469(1975)032<0003:TEODTC $>2.0$.CO;2.

Mayer, M., L. Haimberger, J. M. Edwards, and P. Hyder, 2017: Toward consistent diagnostics of the coupled atmosphere and ocean energy budgets. J. Climate, 30, 9225-9246, https:// doi.org/10.1175/JCLI-D-17-0137.1; Corrigendum, 31, 29772978, https://doi.org/10.1175/JCLI-D-17-0855.1.

Merchant, C. J., and Coauthors, 2012: A 20 year independent record of sea surface temperature for climate from along-track scanning radiometers. J. Geophys. Res., 117, C12013, https:// doi.org/10.1029/2012jc008400.

_ , and Coauthors, 2014: Sea surface temperature datasets for climate applications from phase 1 of the European space agency Climate Change Initiative (SST CCI). Geosci. Data J., 1, 179-191, https://doi.org/10.1002/gdj3.20.

, and Coauthors, 2019: Satellite-based time-series of seasurface temperature since 1981 for climate applications. Sci. Data, 6, 223, https://doi.org/10.1038/s41597-019-0236-x.

Miralles, D., and Coauthors, 2014: El Niño-La Niña cycle and recent trends in continental evaporation. Nat. Climate Change, 4, 122-126, https://doi.org/10.1038/nclimate2068.

Power, S. B., T. Casey, C. Folland, A. Colman, and V. Mehta, 1999: Interdecadal modulation of the impact of ENSO on Australia. Climate Dyn., 15, 319-324, https://doi.org/10.1007/s003820050284.

Rayner, N. A., P. Brohan, D. E. Parker, C. K. Folland, J. J. Kennedy, M. Vanicek, T. J. Ansell, and S. F. B. Tett, 2006: 
Improved analyses of changes and uncertainties in sea surface temperature measured in situ since the mid-nineteenth century: The HadSST2 dataset. J. Climate, 19, 446-469, https:// doi.org/10.1175/JCLI3637.1.

Reynolds, R. W., 2009: What's new in version 2. OISST, www.ncdc. noaa.gov/sites/default/files/attachments/Reynolds2009_oisst_daily_ v02r00_version2-features.pdf.

, T. M. Smith, C. Liu, D. B. Chelton, K. S. Casey, and M. G. Schlax, 2007: Daily high-resolution-blended analyses for sea surface temperature. J. Climate, 20, 5473-5496, https://doi.org/ 10.1175/2007JCLI1824.1.

Ricciardulli, L., and F. J. Wentz, 2015: A scatterometer geophysical model function for high winds: QuikSCAT Ku-2011. J. Atmos. Oceanic Technol., 32, 1829-1846, https://doi.org/10.1175/ JTECH-D-15-0008.1.

Roberts, J. B., C. A. Clayson, F. R. Robertson, and D. L. Jackson, 2010: Predicting near-surface atmospheric variables from Special Sensor Microwave/Imager using neural networks with a first-guess approach. J. Geophys. Res., 115, D19113, https://doi.org/10.1029/2009JD013099.

,$- \longrightarrow$ and - 2019: Improving near-surface retrievals of surface humidity over the global open oceans from passive microwave observations. Earth Space Sci., 6, 1220-1233, https://doi.org/10.1029/2018ea000436.

,-- , and -2020 : SeaFlux v3: An updated climate data record of ocean turbulent fluxes. https://doi.org/10.5067/ SEAFLUX/DATA101; data available at https://ghrc.nsstc. nasa.gov/pub/SEAFLUX/.

Robertson, F. R., M. G. Bosilovich, J. B. Roberts, R. H. Reichle, R. Adler, L. Ricciardulli, W. Berg, and G. J. Huffman, 2014: Consistency of estimated global water cycle variations over the satellite era. J. Climate, 27, 6135-6154, https://doi.org/ 10.1175/JCLI-D-13-00384.1.

Rodell, M., and Coauthors, 2015: The observed state of the water cycle in the early twenty-first century. J. Climate, 28, 82898318, https://doi.org/10.1175/JCLI-D-14-00555.1.

Roemmich, D., J. Church, J. Gilson, D. Monselesan, P. Sutton, and S. Wijffels, 2015: Unabated planetary warming and its ocean structure since 2006. Nat. Climate Change, 5, 240-245, https:// doi.org/10.1038/nclimate2513.

Schulz, J., P. Schlussel, and H. Grassl, 1993: Water vapour in the atmosphere boundary layer over oceans from SSM/I measurements. Int. J. Remote Sens., 14, 2773-2789, https://doi.org/ 10.1080/01431169308904308.

Shie, C.-L., K. Hilburn, L. S. Chiu, R. Adler, I.-I. Lin, E. Nelkin, J. Ardizzone, and S. Gao, 2012: Goddard satellite-based surface turbulent fluxes, $0.25 \times 0.25 \mathrm{deg}$, daily grid v3. Goddard Earth Sciences Data and Information Services Center (GES DISC), accessed June 2014, https://doi.org/10.5067/MEASURES/ GSSTF/DATA301.

Slivinski, L. C., and Coauthors, 2019: Towards a more reliable historical reanalysis: Improvements for version 3 of the Twentieth Century Reanalysis System. Quart. J. Roy. Meteor. Soc., 145, 2876-2908, https://doi.org/10.1002/qj.3598.

Stammer, D., A. Cazenave, R. M. Ponte, and M. E. Tamisiea, 2013: Causes for contemporary regional sea level changes. Annu. Rev. Mar. Sci., 5, 21-46, https://doi.org/10.1146/annurevmarine-121211-172406.

Swadley, S., G. Poe, D. Kunkee, W. Bell, S. Brown, I. Prata, E. Long, and D. Boucher, 2008: SSMIS calibration anomalies: Observed F-16 and F-17 anomalies, detailed analysis of the root causes, and the path forward. Proc. 16th Int. TOVS Study Conf., Angra dos Reis, Brazil, International TOVS Working
Group, 2 pp., https://cimss.ssec.wisc.edu/itwg/itsc/itsc16/ proceedings/1_8_Swadley.pdf.

Syed, T. H., J. S. Famiglietti, D. P. Chambers, J. K. Willis, and K. Hilburn, 2010: Satellite-based global-ocean mass balance estimates of interannual variability and emerging trends in continental freshwater discharge. Proc. Natl. Acad. Sci. USA, 107, 17 916-17 921, https://doi.org/10.1073/ pnas. 1003292107.

Titchner, H. A., and N. A. Rayner, 2014: The Met Office Hadley Centre sea ice and sea surface temperature data set, version 2: 1. Sea ice concentrations. J. Geophys. Res. Atmos., 119, 2864 2889, https://doi.org/10.1002/2013JD020316.

Tomita, H., T. Hihara, and M. Kubota, 2018: Improved satellite estimation of near-surface humidity using vertical water vapor profile information. Geophys. Res. Lett., 45, 899-906, https:// doi.org/10.1002/2017GL076384.

,-- S. Kako, M. Kubota, and K. Kutsuwada, 2019: An introduction to J-OFURO3, a third-generation Japanese ocean flux data set using remote-sensing observations. J. Oceanogr., 75, 171-194, https://doi.org/10.1007/s10872-018-0493-x.

Trenberth, K. E., 1991: Climate diagnostics from global analyses: Conservation of mass in ECMWF analyses. J. Climate, 4, 707722, https://doi.org/10.1175/1520-0442(1991)004<0707:CDFGAC> 2.0.CO;2.

_ 1997: Using atmospheric budgets as a constraint on surface fluxes. J. Climate, 10, 2796-2809, https://doi.org/10.1175/15200442(1997)010<2796:UABAAC $>2.0$.CO;2.

— , and C. Guillemot, 1998: Evaluation of the atmospheric moisture and hydrological cycle in the NCEP/NCAR reanalyses. Climate Dyn., 14, 213-231, https://doi.org/10.1007/ s003820050219.

_ - and J. T. Fasullo, 2013: Regional energy and water cycles: Transports from ocean to land. J. Climate, 26, 7837-7851, https://doi.org/10.1175/JCLI-D-13-00008.1.

_ energetics formulation. J. Climate, 31, 6263-6279, https:// doi.org/10.1175/JCLI-D-17-0838.1.

$\longrightarrow, \ldots$, and J. Mackaro, 2011: Atmospheric moisture transports from ocean to land and global energy flows in reanalyses. J. Climate, 24, 4907-4924, https://doi.org/10.1175/2011JCLI4171.1.

Vecchi, G. A., B. J. Soden, A. T. Wittenberg, I. M. Held, A. Leetmaa, M. J. Harrison, 2006: Weakening of tropical Pacific atmospheric circulation due to anthropogenic forcing. Nature, 441, 73-76, https://doi.org/10.1038/nature04744.

von Schuckmann, K., and Coauthors, 2016: An imperative to monitor Earth's energy imbalance. Nat. Climate Change, 6 , 138-144, https://doi.org/10.1038/nclimate2876.

Wentz, F. J., 2013: SSM/I version-7 calibration report. RSS Tech. Rep. 011012, 46 pp., http://images.remss.com/papers/rsstech/ 2012_011012_Wentz_Version-7_SSMI_Calibration.pdf.

_ 2015: A 17-yr climate record of environmental parameters derived from the Tropical Rainfall Measuring Mission (TRMM) microwave imager. J. Climate, 28, 6882-6902, https://doi.org/10.1175/JCLI-D-15-0155.1.

- C. A. Mears, and NOAA CDR Program, 2013: NOAA Climate Data Record (CDR) of SSM/I and SSMIS microwave brightness temperatures, RSS version 7. NOAA National Centers for Environmental Information, accessed January 2019, https://doi.org/10.7289/V5SJ1HKZ.

- and Coauthors, 2017: Evaluating and extending the ocean wind climate data record. IEEE J. Sel. Top. Appl. Earth Obs. Remote Sens., 10, 2165-2185, https://doi.org/10.1109/JSTARS. 2016.2643641. 
Woodruff, S. D., and Coauthors, 2011: ICOADS release 2.5: Extensions and enhancements to the surface marine meteorological archive. Int. J. Climatol., 31, 951-967, https://doi.org/ 10.1002/joc. 2103 .

Yu, L., 2019: Global air-sea fluxes of heat, fresh water, and momentum: Energy budget closure and unanswered questions. Annu. Rev. Mar. Sci., 11, 227-248, https://doi.org/10.1146/ annurev-marine-010816-060704.

_, and R. A. Weller, 2007: Objectively analyzed air-sea heat fluxes for the global ice-free oceans (1981-2005). Bull. Amer.
Meteor. Soc., 88, 527-540, https://doi.org/10.1175/BAMS-88-4527.

Zhang, H., A. Clement, and P. Di Nezio, 2014: The South Pacific meridional mode: A mechanism for ENSO-like variability. J. Climate, 27, 769-783, https://doi.org/10.1175/JCLI-D-1300082.1.

Zhang, Y., J. M. Wallace, and D. S. Battisti, 1997: ENSO-like interdecadal variability: 1900-93. J. Climate, 10, 1004-1020, https://doi.org/10.1175/1520-0442(1997)010<1004:ELIV> 2.0.CO;2. 